\title{
ÁREAS PRIORITÁRIAS NA AMAZÔNIA PARA CONSERVAÇÃO DOS RECURSOS GENÉTICOS DE ESPECIES FLORESTAIS NATIVAS: FASE PRELIMINAR
}

\author{
Angela Maria Conte Leite ${ }^{1}$ \\ Eduardo Lleras ${ }^{1}$
}

Recebido em 25-5-92. Aceito em 24-4-93

\begin{abstract}
RESUMO - O CENARGEN/EMBRAPA está realizando a prospecção das áreas prioritárias para a conservação in situ dos recursos genéticos de espécies com importância sócio-econômica para cada bioma existente no Brasil, buscando a conservação da variabilidade genética das mesmas. Para a prospecção da floresta tropical úmida amazônica, inicialmente foram feitos levantamentos de herbários nacionais bem como de literatura, para tentar definir os padrōes de distribuição geográfica de algumas espécies prioritárias da regiảo. A ocorrência das mesmas foi correlacionada com solos, clima, vegetação e com a existência de unidades de conservação na Amazônia, no intuito de se propôr as áreas mais adequadas para a implantação de reservas genéticas (conservaçāo in situ) e de bancos de germoplasma (conservação ex situ à campo). As espécies relatadas no presente trabalho são Aniba rosaeodora Ducke (pau-rosa), Bertholletia excelsa H.B.K. (castanha-do-Pará), Carapa quianensis Aubl. (andiroba), Cedrela fissilis Vell. e C. odorata L. (cedros), Copaifera langsdorffii Desf. e C. multijuga Hayne (copaíbas), Cordia goeldiana Huber (freijó), Jacaranda copaia (Aubl.) D. Dom (pará-pará), Simaruba amara Aubl. e Virola sebifera Aubl. e V. surinamensis Warb. (ucuúbas) e Voucapoua americana Aubl. e V. pallidor Ducke (acapús). Trabalhos posteriores com as mesmas incluirão a corroboração à campo dos dados obtidos nos herbários e na literatura, bem como estudos a nível de população dentro das áreas selecionadas.
\end{abstract}

Palavras Chaves: Amazônia, Bancos de Germoplasma, Conservação, Espécies Prioritárias, Reservas Genéticas.

ABSTRACT - CENARGEN/EMBRAPA is investigating priority areas for in situ conservation of genetic resources of socially and economically important species. Herbaria and the literature were consulted to determine the distribution patterns

1 Centro Nacional de Pesquisa de Recursos Genéticos e Biotecnologia - CENARGEN/ EMBRAPA, Cx. P. 02372, 70.849, Brasília, D.F. 
of some tropical rain forest species. Known species distribution were correlated with soils, climate, vegetation types and the existence of conservation units, in order to propose the establishment of genetic reserves for in situ conservation and field gene banks for ex situ conservation. The species reported here are Aniba rosaedora Ducke (rosewood), Bertholletia excelsa H.B.K. (Brazil nut), Carapa quianensis Aubl. (andiroba), Cedrela fissilis Vell. e C. odorata L. (cedar), Copaifera langsdorffii Desf. e C. multijuga Hayne (copaîbas), Cordia goeldiana Huber (freijó), Jacaranda copaia (Aubl.) D. Dom (pará-pará), Simaruba amara Aubl. (marupá), Swietenia macrophylla King (mahogany), Virola sebifera Aubl. e V. surinamensis Warb. (ucuúbas) e Voucapoua americana Aubl. e V. pallidior Ducke (acapú). Further work will include field corroboration of the data presented here, as well as population studies in the selected areas.

Key words: Amazônia, Field Gene Banks, Genetic Reserves, Conservation, Tropical Forest Species

\section{Introdução}

A conservação dos recursos genéticos de espécies nativas da Amazônia oferece desafios, tanto pelas dimensōes territoriais da região quanto pela quantidade ainda insuficiente de dados sobre as espécies.

Para propôr áreas convenientes e de caráter imediato para conservação genética das espécies consideradas pensou-se, primordialmente, nas Unidades de Conservação já existentes na Amazônia, a cargo principalmente de Instituições Federais, Estaduais e de Pesquisa. Essas áreas, por estarem protegidas por lei, oferecem garantia de conservação das espécies. Entretanto, muitas dessas Unidades de Conservação carecem dos levantamentos florísticos e somente alguns pontos de ocorrência nas proximidades das mesmas, em mesmo tipo de ambiente, permitiram inferir sobre os melhores locais para conservação, dentro dessas áreas protegidas. Outras Unidades, entretanto, apresentam levantamentos florísticos bem detalhados, como por exemplo a Floresta Nacional do Tapajós, a Estação Ecológica do Jarí, a Reserva Florestal Ducke e a Reserva Biológica do INPA/ SUFRAMA.

Somente a conservação in situ de cada espécie não permitirá a conservação de toda variabilidade genética possível de existir em cada uma. Por isso, são também propostos locais para implantação de populaçōes base ou Bancos de Germoplasma, onde a variabilidade genética das populações não contempladas pela conservação in situ estariam asseguradas a campo, permitindo assim, a conservação da maior gama possível de variabilidade genética para cada espécie, nas mesmas regiōes e condições de ocorrência natural delas. Por isso, e também como garantia, são sugeridos sempre mais de um local para implantação dos Bancos de Germoplasma (populações base), utilizando-se portanto a conservação 
tanto in situ quanto ex situ (a campo) para conservação da variabilidade genética de cada espécie.

A indicação das Unidades de Conservação como prioritárias para implantação de Reservas Genéticas não deve ser tomada como o único meio adotado pelo CENARGEN para conservação in situ. Ao contrário, indica a preocupação de se tentar, a curto prazo, preservar pelo menos parte da variabilidade genética das espécies mais ameaçadas ou mais utilizadas no contexto sócio-econômico regional, e das quais as populações amazônicas sobrevivem principalmente pelo extrativismo.

Dependento da ocorrência (ampla ou restrita) de cada espécie, são propostos vários locais prioritários para implantação de Reservas Genéticas em Unidades de Conservação já estabelecidas.

\section{Materiais e Métodos}

A distribuição geográfica das espécies foi feita através dos dados obtidos nos principais Herbários Nacionais ( listados a seguir ) e mapeados tomando-se por base os Mapas do IBAMA (19) para localização das Unidades de Conservação.

A seleção das áreas prioritárias foi feita tomando-se por base a ocorrência de cada espécie, as variações em tipos de vegetação, clima e solo relacionados com os padrões de distribuição e a localização das principais Unidades de conservação da região amazoônica

As variações morfológicas apresentadas pela maioria das espécies, segundo a ocorrência ( habitat e distribuição geográfica ), e verificadas a partir dús amostras de herbários também foram importantes para a escolha das áreas prioritárias para conservação dos recursos genéticos.

As espécies escolhidas para este estudo fazem parte de um lista de espécies prioritárias utilizada pelo CENARGEN onde a prioridade de cada uma se deve não só pelo risco de erosão genética mas também pelo potencial de utilização da espécie pelo homem e a necessidade de preservá-la para as gerações futuras.

Assim, as quinze espécies estudadas foram selecionadas com base nos critérios sugeridos por Roche (1987) onde: distribuição ecológica, densidade populacional, capacidade de regeneração, utilização pelo homem, aspectos silviculturais e vulnerabilidade dos habitats foram considerados.

Herbários consultados para obtenção dos dados de distribuição geográfica:

Herbário do Instituto Nacional de Pesquisas da Amazônia/INPA, Manaus Herbário do Museu Paraense Emíllio Goeldi, Belém Herbário da Universidade Federal de Cuiabá 
Herbário do Centro Nacional de Pesquisa Agroflorestal da Amazônia

Oriental/EMBRAPA- CPATU, Belém

Herbário do Jardim Botânico do Rio de Janeiro

Herbário Ezechias Paulo Heringer/Jardim Botânico de Brasília

Herbário do Museu Nacional

Herbário da Universiddade de Brasilia/UnB

Herbário da Universidade Federal de Goiás

Herbário da Reserva Ecológica do IBGE

Herbário do Instituto Agronomico de Campinas/IAC

Herbário Bradeanum

Herbário do Museu Botânico Municipal de Curitiba

Herbário Alexandre Leal Costa/ Universidade Federal da Bahia

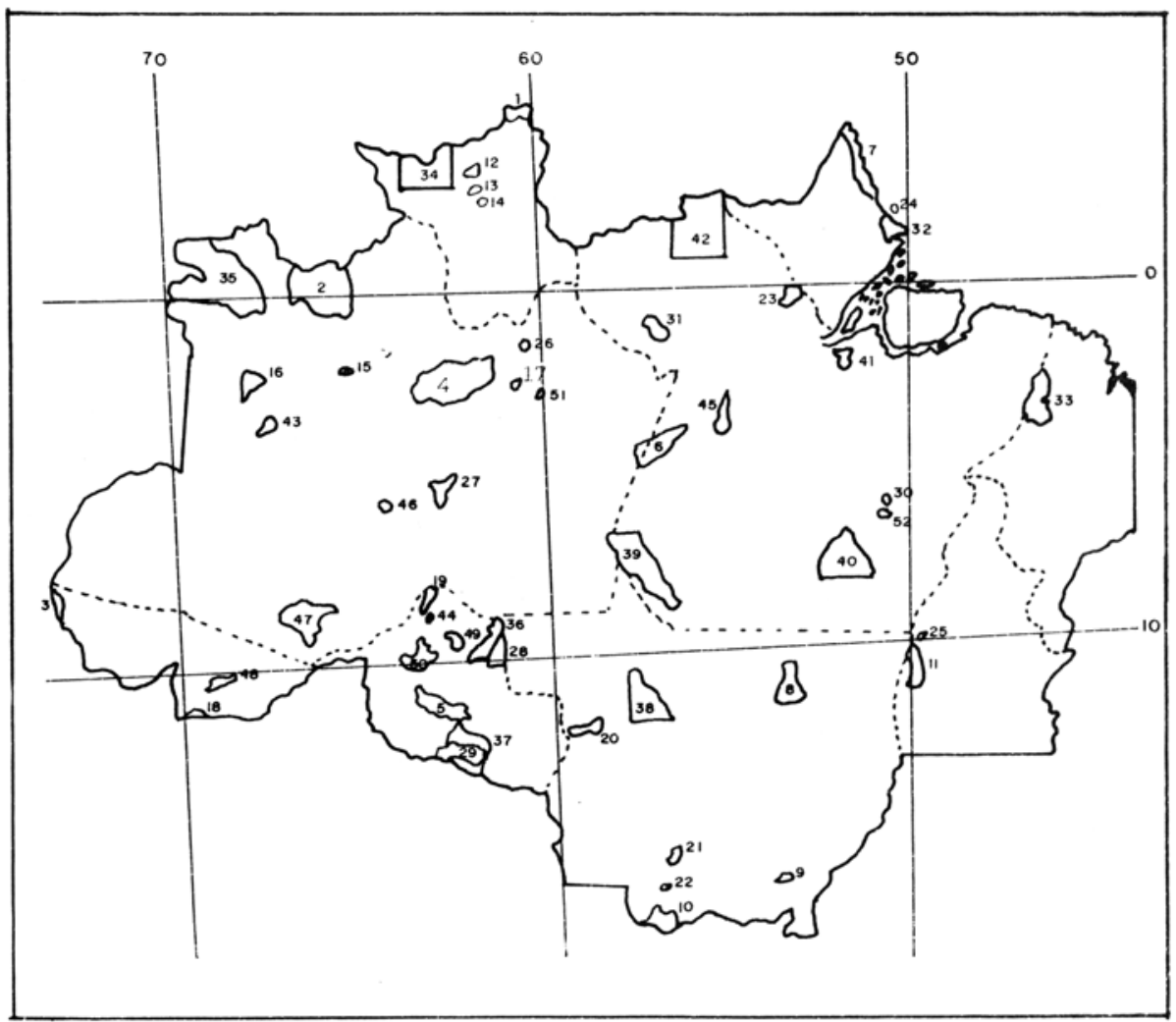

Figura 1. Principais Unidades de Conservação na Amazônia Brasileira 
Unidades de conservação na região Amazônica

Parques Nacionais

1. Monte Roraima

2. Pico da Neblina

3. Serra do Divisor

4. Jaú

5. Pacaás-Novos

6. Amazônia

7. Cabo Orange

8. Xingú

9. Chapada dos Guimarães

10. Pantanal

11. Araguaia

Estaçōes Ecológicas

12. Maracá

13. Caracaraí

14. Miquiá

15. Manirauá

16. Juami-Japurá

17. Anavilhanas

18. Rio Acre

19. Curuá

20. Iquê

21. Serra das Araras

22. Taiamá

23. Jarí

24. Maracá-Jipióca

25. Côco Javaés

Reservas Biológicas

26. Uatumã

27. Abufarí

28. Jarú

29. Guaporé
30. Tapirapé

31. Rio Trombetas

32. Lago Piratuba

33. Gurupi

Reservas Florestais

34. Parima

35. Rio Negro

36. Jaru

37. Pedras Negras

38. Juruena

39. Mundurucania

40. Gorotire

41. Caxiuanã

42. Tumucumaque

Estação Estadual

43. Jutái-Solimões

Florestas Nacionais

44. Jamari

45. Tapajós

46. Tefé

47. Purús

48. Maçanã

49. Jamari

50. Bom Futuro

Reserva Estadual

51. Suim-Castanheira

Área de Proteção Aminal

52. Igarapé Gelado 


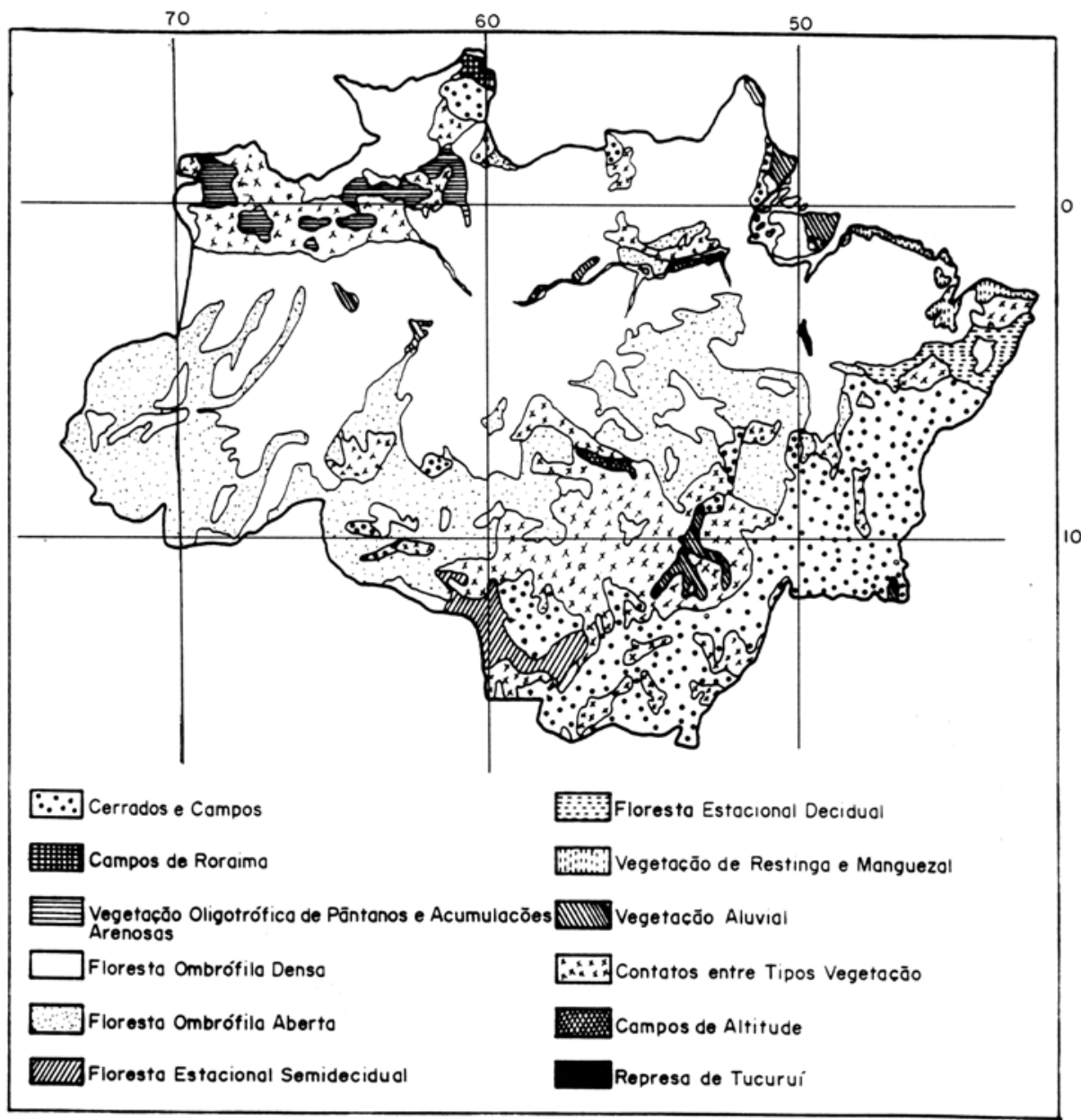

Figura 2 - Principais tipos de vegetação na Amazônia Brasileira. Adaptado de IBGE/IBDF ( Mapa de Vegetação do Brasil, 1988)

\section{Resultados e Conclusões}

Proposta de conservação:

Aniba rosaeodora Ducke

Familia: Lauraceae

Nomes vernaculares: Pau-rosa, Bois de rose femelle (G. Francesa) e caracara (Guyana)

Habitat: Habita preferencialmente forestas pluviais altas, podendo ocorrer espo- 
radicamente em florestas baixas de areia branca da região do Rio Negro ( Campinas e Caatingas ) e em áreas de igapós ( floretas inundadas ) na região do Rio Mapuer ( Pará). Distribui-se pelas regiões de clima tipos Am e Aw (pluviosidade elevada ) e solos do tipo latossolos ( amarelos e vermelhos ) e podzols gley, e em solos originários de formações do alto carbonífero apresenta maior produtividade. Fenologia: floração e frutificação são variáveis segundo a ocorrência da espécie.

\begin{tabular}{llll}
\hline Autores & Local & Floração & Frutificação \\
\hline $\begin{array}{l}\text { Loureiro \& } \\
\text { Silva (1968) }\end{array}$ & $\begin{array}{l}\text { Manaus e Alto } \\
\text { Rio Amazonas }\end{array}$ & ABR. - MAI. & $2^{2}$ semestre \\
Araújo (1970) & Manaus & OUT.-NOV. & JUN.-JUL \\
Carvalho (1983) & FLONA Tapajós & ABR.-MAI. & $\begin{array}{l}\text { subsequente/ } \\
\text { simultânea }\end{array}$ \\
$\begin{array}{l}\text { Kubitzki } \\
\text { \& Renner (1982) }\end{array}$ & $\begin{array}{l}\text { Amaz. Central } \\
\text { Amaz. Oriental }\end{array}$ & $\begin{array}{l}\text { todo ano } \\
\text { FEV.-ABR. }\end{array}$ & \\
& GAianas & MAR.-NOV. & \\
FAO (1986) & Amazônia & $\begin{array}{l}\text { ABR.-MAI. } \\
\text { (irregular) }\end{array}$ & $\begin{array}{l}\text { irregular/ } \\
\text { comprometida }\end{array}$ \\
\hline
\end{tabular}

Importância econômica

A espécie vem sendo explorada desde o século passado na região das Guianas e neste século na Amazônia Central para extração do linalol, essência empregada na indústria de perfumaria.

Embora em risco de erosão genética, ainda os caboclos regionais distiguem 3 tipos de pau-rosa segundo a coloração do lenho:

1 .pau-rosa mulatinho (quase escuro, de densidade elevada cujas toras submergem quando atiradas à água; mais rico em essência ).

2. pau-rosa itáuba ( cor amarelada, menos denso que o anterior

3. pau-rosa imbaúba (cor quase branca, muito leve; menos rico em essência)

Em Maués, um dos centros de maior densidade da espécie, os extrativistas locais distinguem 3 tipios de pau-rosa (Jean-Paul Lescure, com. pess) conforme o rendimento em óleo essencial.

1. Tucuribá ( $151 /$ ton )

2. Imbaúba (10 1/ton )

3. Cheirosa ( $<101 /$ ton )

Locais onde supostamente está conservada (in situ) e propostas $\left({ }^{*}\right)$ para implantação de reservas genéticas: 
Reserva Florestal Walter Egler

* Reserva Florestal Ducke

* Reserva Nacional do Tapajós

* Parque Nacional da Amazônia

* Reserva Florestal do Rio Negro

Parque Nacional da Serra do Divisor

Locais sugeridos para conservação ex situ pela implantação de bancos de germoplasma (populaçōes base)

Reserva Florestal Ducke

Floresta Nacional do Tapajós

Estação Ecológica do Jarí

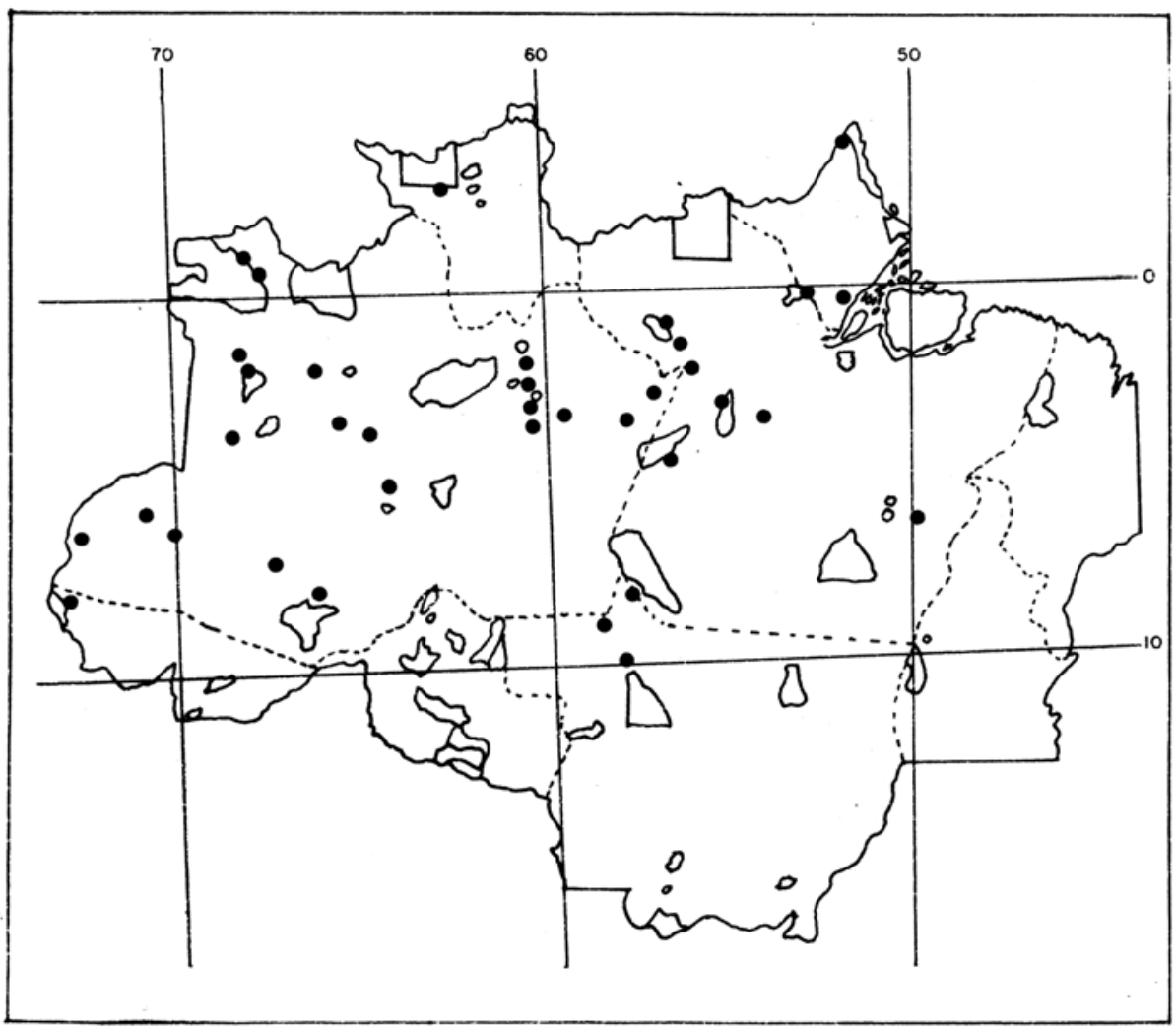

Figura 3. Distribuição geográfica de Aniba rosaeodora Ducke. Pau-rosa. 
Bertholletia excelsa H. B. K.

Família: Lecythidaceae

Nomes vernaculares: Castanha do Pará, do Brasil.

Habitat: Em matas de terra firme, amplamente espalhada por toda a região amazônica, em grupamentos denominados castanhais.

Fenologia: $\left({ }^{*}\right)$

JAN. FEV. MAR. ABR. MAI. JUN. JUL. AGO. SET. OUT. NOV. DEZ.

\section{XXXXX Floração …. Frutificação}

${ }^{(*)}$ pode haver variação pouco acentuada, dependendo da ocorrência.

Importância econômica:

Explorada de maneira extrativa, em toda Amazônia, desde a época prácolombiana. A exportação do produto, principalmente para Europa e Estados Unidos, intensificou-se no início deste século.

Locais onde supostamente está conservada (in situ) e propostas $\left(^{*}\right)$ para implantação de reservas genéticas:

* Reserva Florestal do Rio Negro

* Parque Nacional da Amazônia

* Reserva Biológica do Tapirapé

* Estação Ecológica Rio Acre Reserva Florestal do Jarú Reserva Florestal Juruena Floresta Nacional do Purús Reserva Biológica Rio Trombetas

* Reserva Estadual Sauim-Castanheira Reserva Florestal Mundurucania

Locais sugeridos para conservação ex situ pela implantação de bancos de germoplasma (populaçōes base): PARÁ

ACRE (já existe um BAG com 16 acessos em Rio Branco) AMAZONAS e 


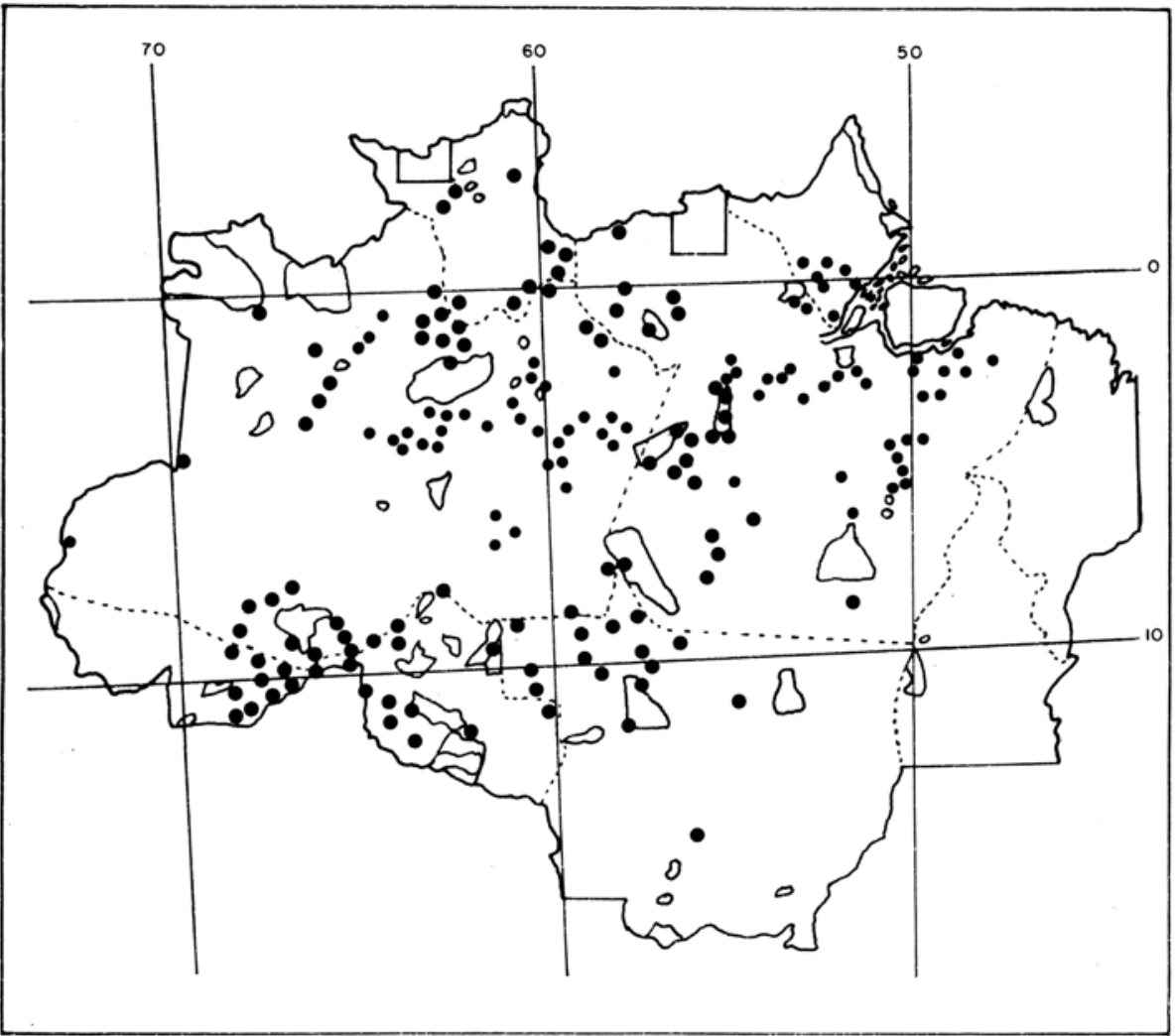

Figura 4. Distribuição geográfica de Bertholletia excelsa H.B.K. Castanha-do-Pará

Carapa guiananses Aubl.

Família: Meliaceae

Nome Vulgar: Andiroba

Habitat: Habita matas de terra firme, várzeas e igapós, áreas inundadas de margens de igarapés.

Fenologia:

JAN. FEV. MAR. ABR. MAI. JUN. JUL. AGO. SET. OUT. NOV. DEZ. 
Importância econômica:

Altamente importante como espécie medicinal, cujo óleo (de andiroba) é comercializado na região e no Brasil, e nas últimas décadas exportado para indústria médica e cosmética. A madeira é considerada sucedânea do Mogno, visto a boa qualidade e o fato de não ser atacada pelo cupim; própria para marcenaria.

Locais onde supostamente está conservada (in situ) e propostas $\left(^{*}\right)$ para implantação de reservas genéticas:

* Reserva Florestal Ducke

* Reserva Florestal de Caxiuanã

Estação Estadual Jutaí-Solimões

Estação Ecológica de Cuniá

* Estação Ecológica do Jarí

* Floresta Nacional do Tapajós

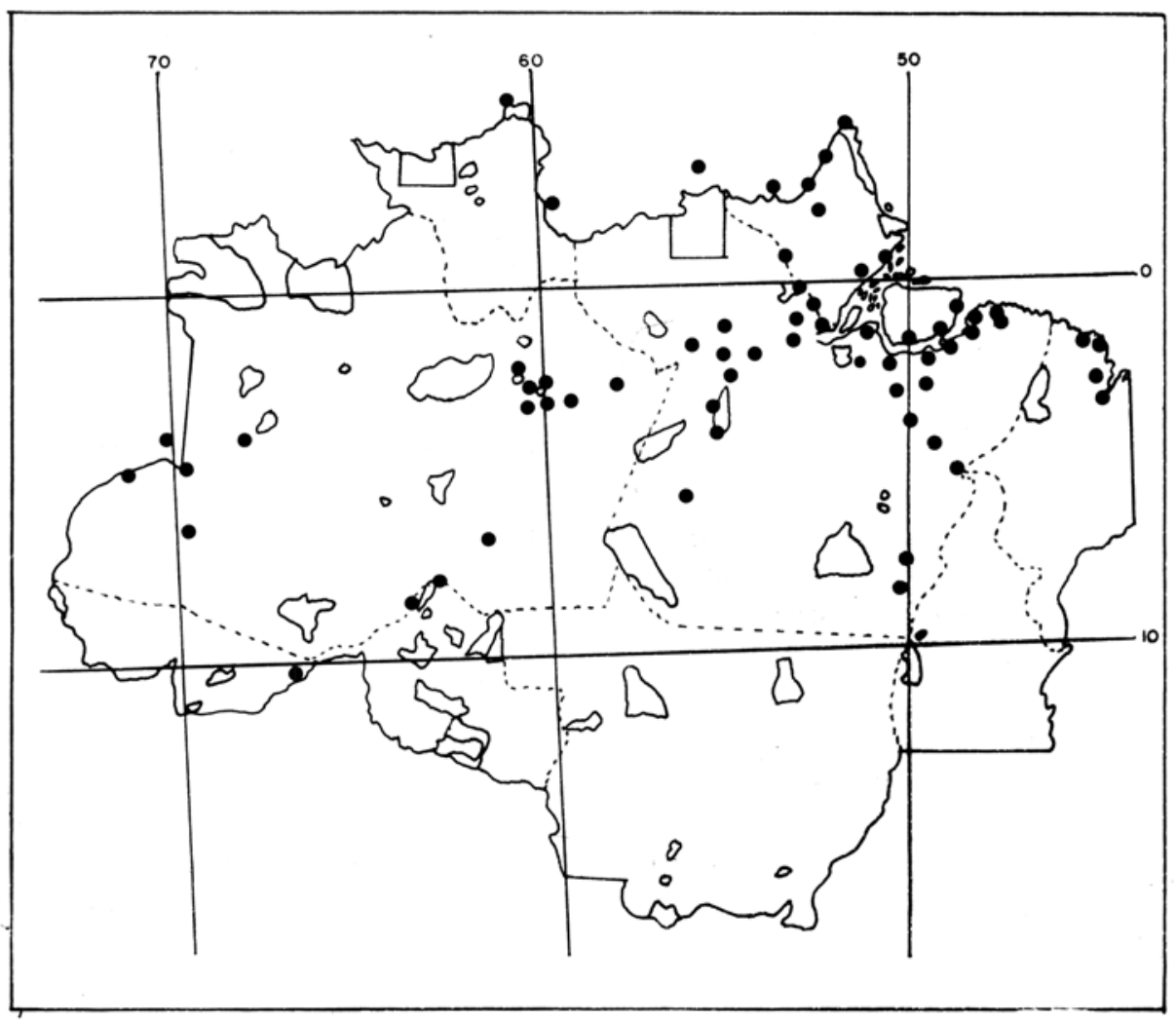

Figura 5 - Distribuição geográfica de Carapa guianensis Aubl. Ändiroba. 
Locais sugeridos para conservação ex situ pela implantação de bancos de germoplasma (populaçōes base):

Estação Experimental de Silvicultura Tropical do INPA (Manaus-AM).

Estação Experimental da SPSB (Imperatriz-MA).

Cedrela fissilis Vell.

Família: Meliaceae

Nome Vulgar: Cedro

Habitat: A espécie ocorre desde a Costa Rica até a Argentina e prefere solos férteis e bem drenados de florestas pluviais de altitude do tipo floresta ombrófila aberta e floresta ombrófila densa.

Fenologia:

JAN. FEV. MAR. ABR. MAI. JUN. JUL. AGO. SET. OUT. NOV. DEZ.

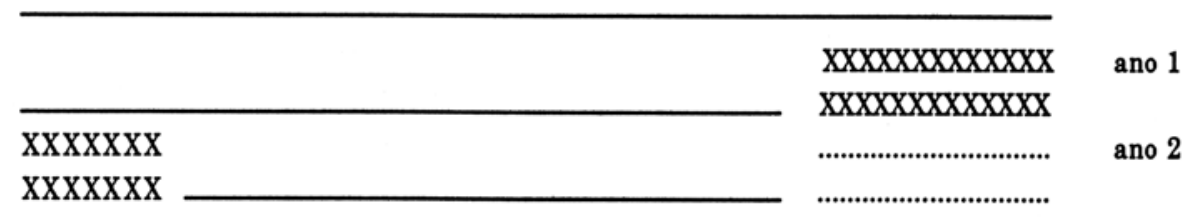

XXXXX Floração ..... Frutificação

Importância econômica:

Embora a madeira de Cedrela fissilis seja menos durável que a de $C$. odorata, ambas são exportadas industrialmente como se fossem a mesma. É menos susceptível ao ataque de Hypsipyla que $C$. odorata.

Locais onde supostamente está conservada (in situ) e propostas (*) para implantação reservas genéticas:

* Reserva Biológica do Jarú

* Reserva Florestal de Mundurucania

* Reserva Biológica do Gurupí

Locais sugeridos para conservação ex situ pela implantação de bancos de germoplasma (populaçöes base):

Em áreas de baixa incidência da espécie, sob a forma de plantios consorciados de $C$. fissilis com outras espécies, que não Meliaceae, preferencialmente na regiãode:

Manaus

Santarém

Imperatriz do Maranhão 


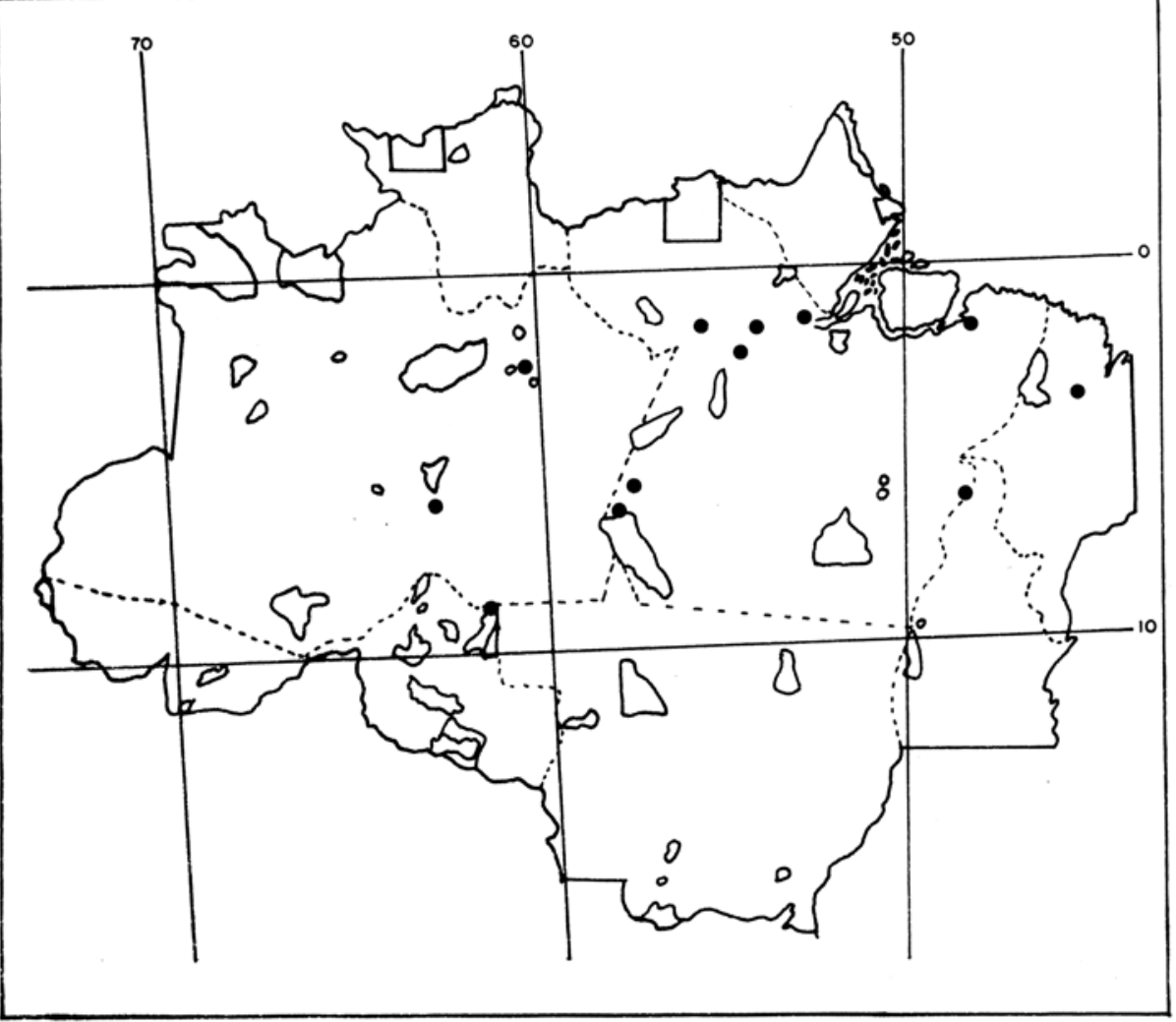

Figura 6 - Distribuição geográfica de Cedrela Fissilis Vell. Cedro.

Cedrela odorata L.

Família: Meliaceae

Nome vulgar: Cedro (Spanish Cedar, mundialmente)

Habitat: Habita áreas de floresta tropical úmida do tipo ombrófila densa ou aberta, distribuindo-se desde o México até a Argentina; ocorre na Amazônia, Nordeste, Sudeste e Centro do Brasil. Atinge a região dos Cerrados através das matas de galeria. Tem preferência por solos ricos e bem drenados.

Fenologia: 
JAN. FEV. MAR. ABR. MAI. JUN. JUL. AGO. SET. OUT. NOV. DEZ.

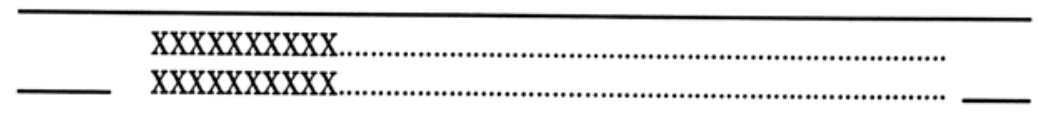

XXXXX Floração Frutificação

Importância econômica

A principal é o valor comercial de sua madeira, mundialmente conhecida, e utilizada para marcenaria.

Locais onde supostamente está conservada (in situ) e propostas (*) para implantação de reservas genéticas:

* Reserva Biológica do Jarú

* Estação Ecológica Rio Acre

* Reserva Florestal Juruena

* Floresta Nacional do Tapajós

Parque Nacional do Xingú

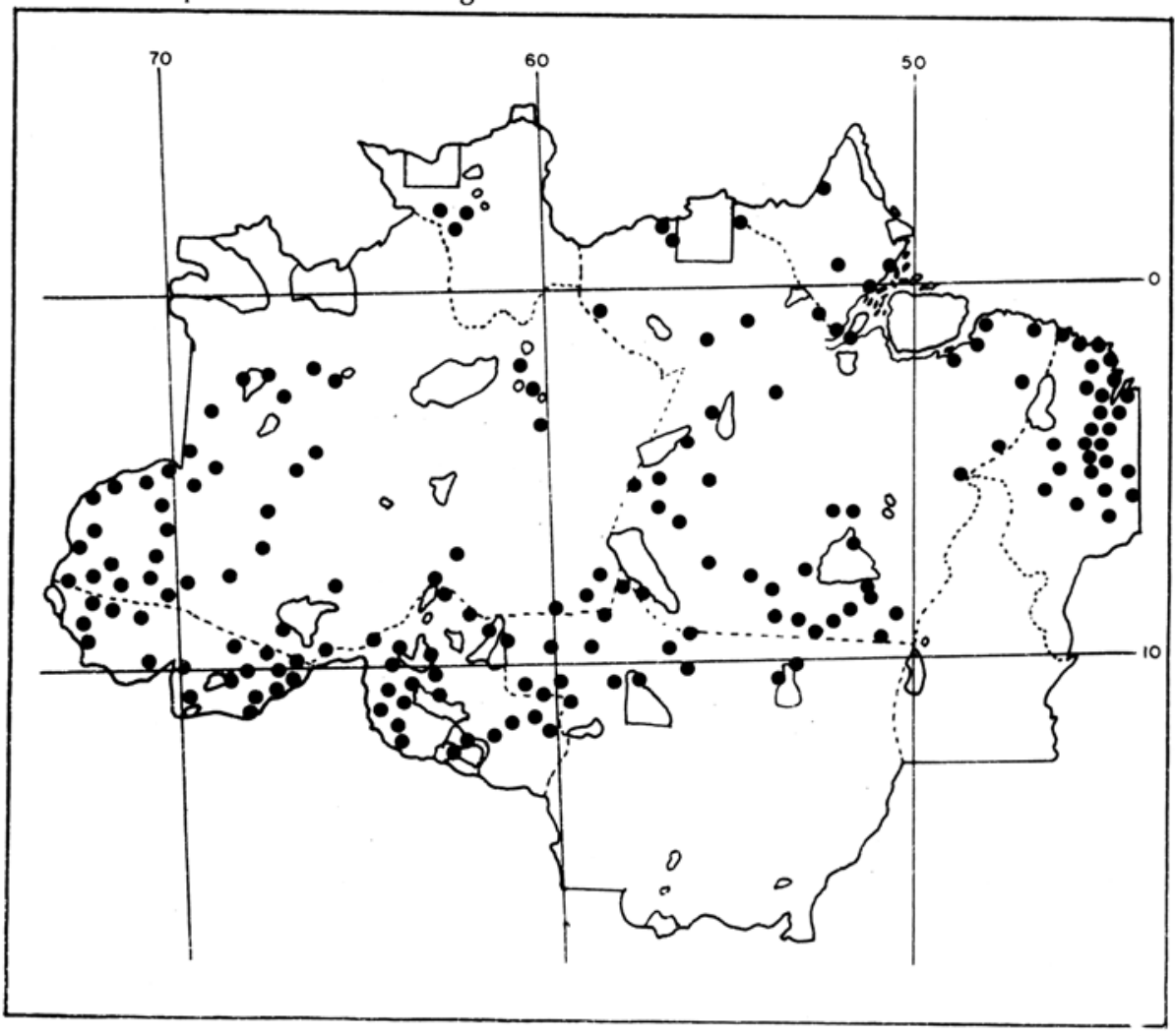

Figura 7 - Distribuição geográfica de Cedrela odorata L. Cedro. 
Reserva Florestal Gorotire

Estação Estadual Jutaí-Solimões

Parque Nacional Pacaás - Novos

Locais sugeridos para conservação ex situ pela implantação de bancos de germoplasma (populações base):

Em áreas de baixa incidência da espécie, sob a forma de plantios consorciados de $C$. odorata com outras espécies, que não Meliaceae, preferencialmente nas regiōes de:

Manaus

Santatém

Imperatriz do Maranhão

\section{Copaifera langsforffii Desf.}

C. langsdorffii var. grandiflora C. langsdorffii var. grandifolia

C. langsdorffii var. laxa C. langsforffii var. glabra

Familia: Caesalpiniaceae

Nomes vernaculares: copaíba, copaíba folha fina, copaíba vermelha, pau d'óleo.

Habitat: Áreas de terra firme, cerrados e campos. É marcadora de terras de qualidade inferior, salvo quando ocorre em mata virgem. Distribui-se desde as Guianas até o Paraná. Apresenta diferenças morfológicas marcantes segundo o habitat (expressas pelas variedades botânicas que possui), principalmente no tocante à madeira, porte, produção de óleo, além dos caracteres morfológicos de folhas, flôres e frutos.

Fenologia: Floração e frutificação variam em função da ocorrência da espécie. Para Amazônia, tais eventos podem ser expressos conforme o quadro abaixo:

JAN. FEV. MAR. ABR. MAI. JUN. JUL. AGO. SET. OUT. NOV. DEZ.

$\begin{array}{llllll}x x x & x x x & x x x & x x x & x x x & x x x\end{array}$ $\mathrm{Xxx} \quad \mathrm{xxx}$

$\begin{array}{lllll}\mathrm{XxX} & \mathrm{XXX} & \mathrm{XxX} & \mathrm{XxX}\end{array}$

XXXXX Floração …. Frutificação

Importância econômica:

Além de madeira, a espécie é principalmente medicinal. Perfurando-se o caule, obtem-se o "óleo de copaíba", comercializado no mercado nacional e exterior e por isso mundialmente conhecido. É utilizado contra numerosas enfermidades, desde cicatrizante, estimulante e espectorante até anti-tetânico. É aproveitado na iluminação doméstica por seringueiros e sertanejos. 
A espécie em questão é menos comum na Amazônia que C. multijuga.

Locais onde supostamente está conservada (in situ) e propostas ( ${ }^{*}$ ) para implantação de reservas genéticas (apenas para Amazônia):

* Parque Nacional Chapada dos Guimarães

* Parque Nacional de Pacaás-Novos

Reserva Biológica do Guaporé

* Reserva Florestal de Pedras Negras

Locais sugeridos para conservação ex situ pela implantação de bancos de germoplasma (populaçōes base): Amazonas e Rondônia.

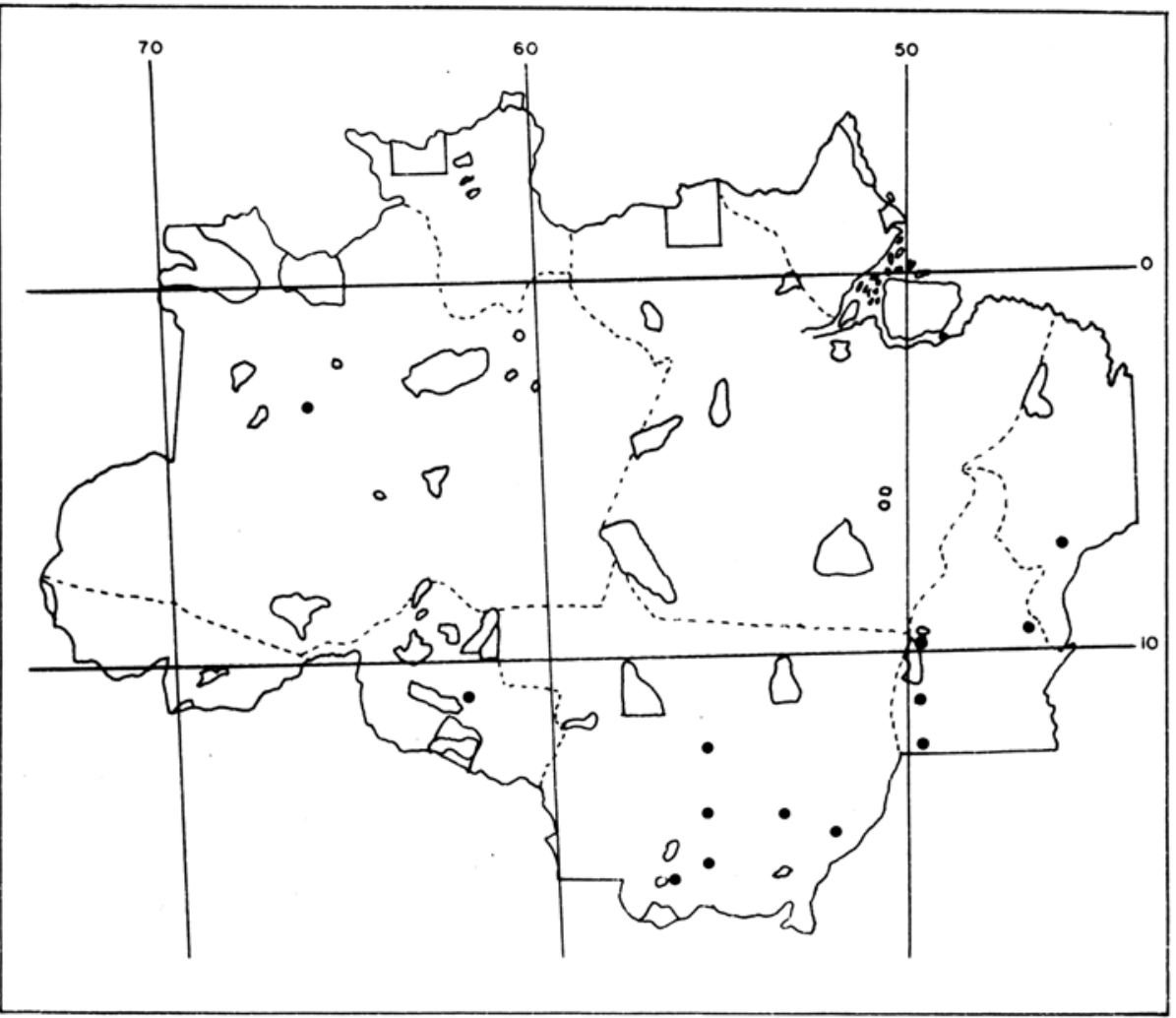

Figura 8 - Distribuição geográfica de Copaifera langsdorffii Desf. Copaíba 
Copaifera multijuga Hayne

Familia: Caesalpiniaceae

Nomes vernaculares: copaíba, copaíba branca, copaíba roxa, copaíba angelim. Habitat: Prefere as matas de terra firme argilosas podendo ocorrer esporadicamente em solos arenosos, na Amazônia.

Fenologia:

JAN. FEV. MAR. ABR. MAI. JUN. JUL. AGO. SET. OUT. NOV. DEZ.

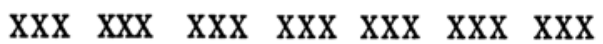

\section{XXXXX Floração _.... Frutificação}

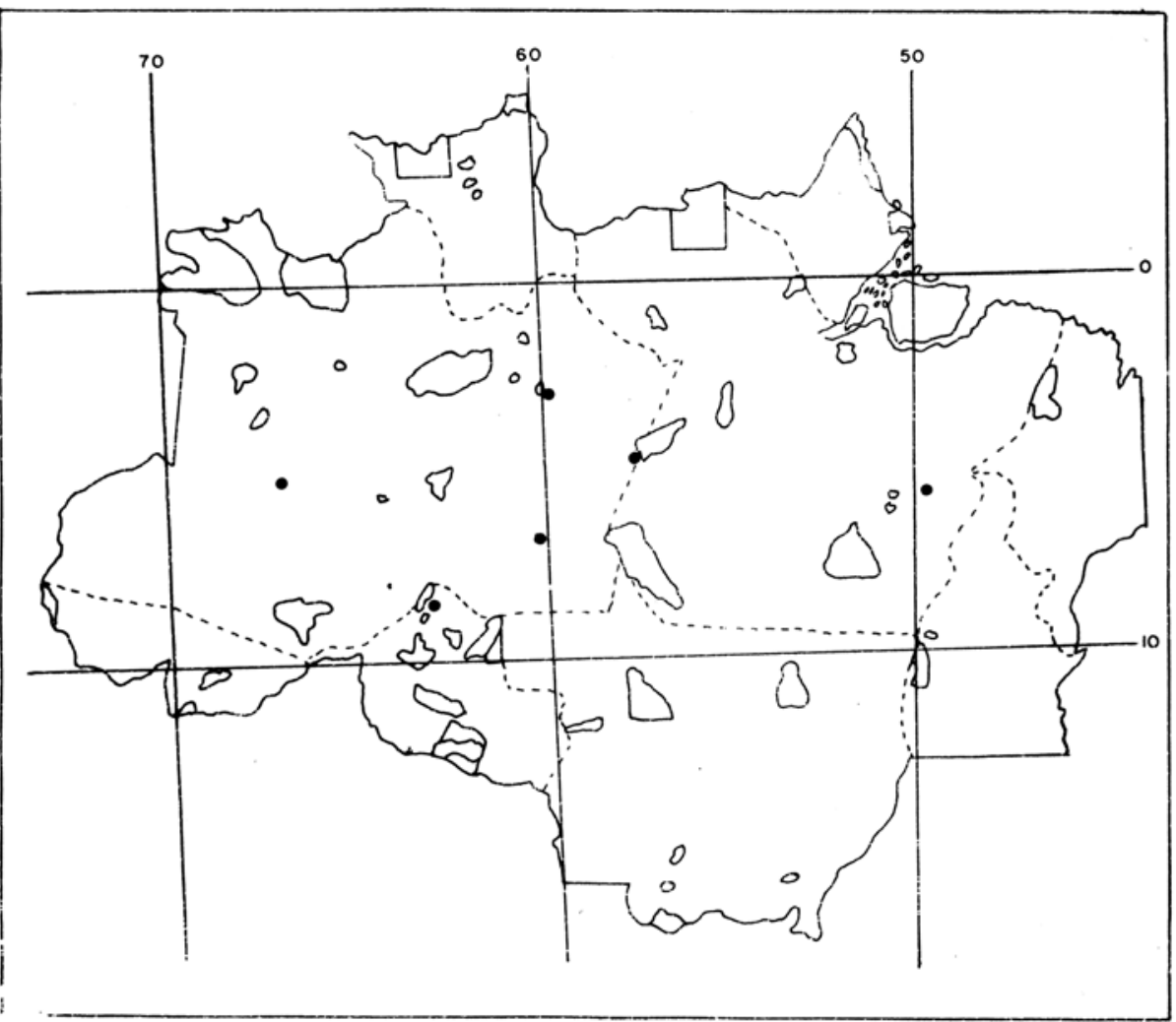

Figura 9 - Distribuição geográfica de Copaifera multijuga Hayne. Copaíba. 
Importância econômica:

A espécie, como a anterior, é medicinal, fornecendo abundante quantidade de óleo flúido e claro. A madeira dessa espécie e menos explorada que a da anterior por sua qualidade mole. Também tem emprêgo na utilização doméstica e potencial de utilização industrial (Kerr, 1978). É um dos produtos extrativos da Amazônia que contribui para a economia regional; somente o Estado do Amazonas exportou 101 ton de óleo para o mercado nacional e 433 ton para o exterior, no período de 1974 a 1979 (Alencar, 1982).

Locais onde supostamente está conservada (in situ) e propostas $\left(^{*}\right)$ para implantação de reservas genéticas:

* Reserva Florestal Ducke

* Reserva Florestal Walter Egler

Locais sugeridos para conservação ex situ pela implantação de bancos de germoplasma (populações base):

Amazonas

Acre

Mato Grosso

\section{Cordia goeldiana Huber}

Família: Boraginaceae

Nomes vernaculares: freijó, frei jorge, frejó, freijó cinza

Habitat: Em matas de terra firme na Amazônia.

Fenologia:

JAN. FEV. MAR. ABR. MAI. JUN. JUL. AGO. SET. OUT. NOV. DEZ.

Importância econômica:

A espécie fornece madeira atualmente considerada de primeira qualidade, em virtude do desgaste de outras espécies madeireiras de renome mundial procedentes da Amazônia.

Substitui o carvalho em marcenaria de luxo, é de fácil trabalhabilidade e durável.

É apontada como uma das espécies mais promissoras na renovação dos recursos florestais da Amazônia e na transformação de florestas heterogêneas em 
povoamentos homogêneos de alta produtividade e estabelecimento de plantaçōespiloto (Leão \& Viegas, 1986).

Locais onde supostamente está conservada (in situ) e propostas $\left({ }^{*}\right)$ para implantação de reservas genéticas:

* Floresta Nacional do Tapajós

* Reserva Florestal Ducke

Floresta Nacional de Maçanã

* Estação Ecológica do Jarí

Locais sugeridos para conservação ex situ pela implantação de bancos de germoplasma (populaçōes base):

Belterra, Município de Santarém-PA (já existe plantio estabelecido da espécie, podendo ser revisto o incremento da procedência de materiais)

Região Bragantina, Município de Igarapé-Açu-PA (também com ensaios silviculturais dessa espécie no local).

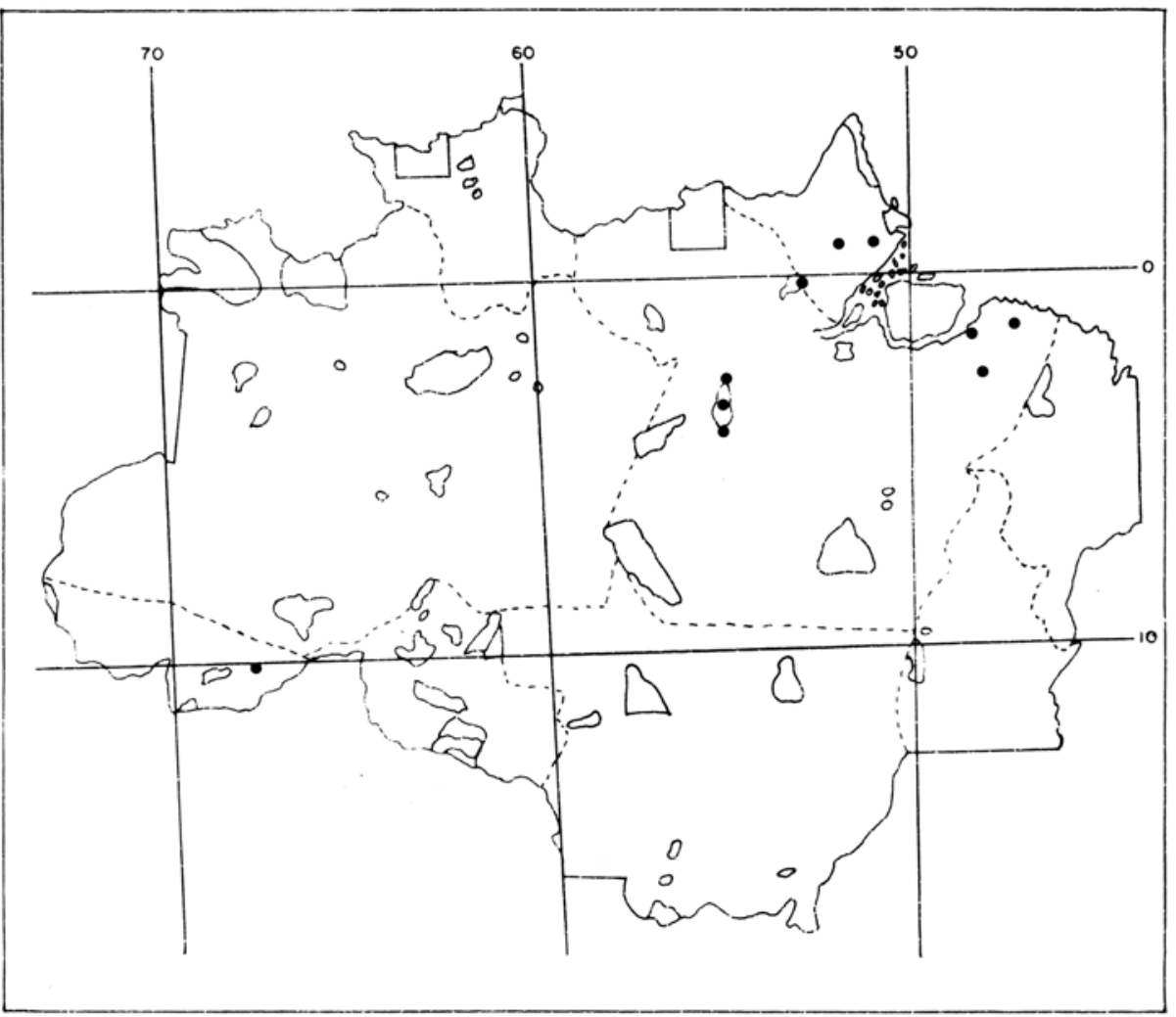

Figura 10 - Distribuição geográfica de Cordia goeldiana Huber. Freijó 
Jacaranda copaia (Aubl.) D. Dom

J. copaia spp. copaia

J. copaia ssp. spectabilis

Família: Bignoniaceae

Nomes vernaculares: Caroba, pará-pará, cajuaçu, marupá, caraúba, carobussú.

Habitat: Habita matas de terra firme e margens de igarpés (várzeas e igapós) na Amazônia: matas de galeria nos Cerrados e regiōes de transição vegetacional. Ocorre em solos tanto argilosos quanto arenosos.

Fenologia:

JAN. FEV. MAR. ABR. MAI. JUN. JUL. AGO. SET. OUT. NOV. DEZ.

Importância econômica:

A raíz, a casca e as folhas têm propriedades medicinais. A madeira é comerciável, embora imprópria para obras externas, pois não resiste ao contacto com a água e a terra (exposição ao tempo).

Locais onde supostamente está conservada (in situ) e porpostas (*) para implantação de reservas genéticas:

${ }^{*}$ Reserva Florestal Ducke

Reserva Florestal Walter Egler

*Reserva Biológica INPA/SUFRAMA

*Floresta Nacional do Tapajós

*Reserva Florestal do Jarí

Locais sugeridos para conservação ex situ pela implantação de bancos de germoplasma (populaçōes base):

Estaçäo Experimental de Silviultura Tropical do INPA, Manaus, para ocorrências do $\mathrm{AM}, \mathrm{AC}, \mathrm{RR}, \mathrm{RO}$ e $\mathrm{MT}$. Guianas.

Estação Experimental de Curuá-Una, para ocorrências do PA, AP e 


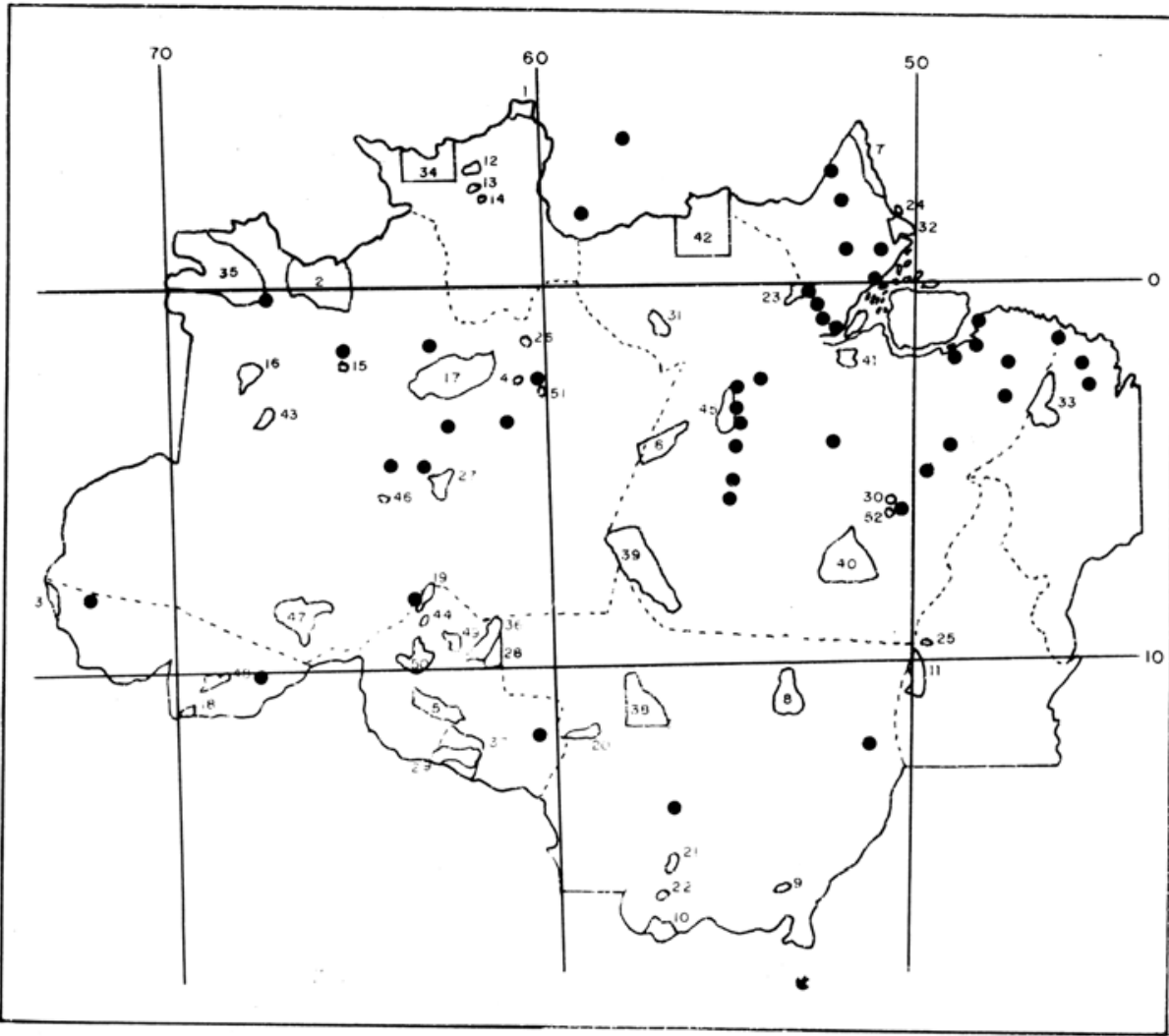

Figura 11 - Distribuição geográfica de Jacaranda copaia (Aubl.) D. Dom. Caroba

Simaruba amara Aubl.

Familia: Simaroubaceae

Nomes vernaculares: marupá, simaruba, tamanqueira, timbuiba, mata menino, paraíba.

Habitat: A espécie é bem diversificada em habitats, ocorrendo desde em matas de terra firme sobre diferentes tipos de solos até áreas inundáveis (várzeas e igapós) de margens de rios e igarapés, savanas, campos arenosos e cerrados.

Essa diversidade de habitats, associada à ampla distribuição geográfica (desde a Amazônia ao Rio de Janeiro), faz com que a espécie apresente diferenças morfológicas, algumas marcantes como por exemplo seu hábito (árvore ou arbusto), em folhas, flôres e frutos.

Fenologia: Varia em função da distribuição geográfica e do habitat, sendo o modêlo mais freqüente, o expresso abaixo: 
JAN. FEV. MAR. ABR. MAI. JUN. JUL. AGO. SET. OUT. NOV. DEZ.

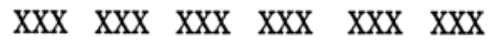

$\mathrm{XXX} \quad \mathrm{XxX}$

ano 1

ano 2

$\mathrm{XXXXX}$ floração ...... frutificação

Importância econômica:

A espécie é fornecedora de madeira de boa qualidade, sendo inclusive indicada para confeç̧ão de instrumentos musicais. Também é usada para marcenaria e fabricação de papel e celulose.

Tem propriedades insetífugas e portanto recomendada para confecção de caixas para guardar documentos e material de herbário para livrá-los do ataque de insetos no decorrer dos anos (c.f. Correa e Penna 1984)

É também medicinal, sendo utilizadas tanto a casca quanto o lenho, as folhas e as raízes no preparo de pocões.

Locais onde supostamente está conservada (in situ) e propostas $\left(^{*}\right)$ para implantação de reservas genéticas (apenas para Amazônia):

* Reserva Biológica Rio Trombetas

* Floresta Nacional do Tapajós

* Reserva Florestal Ducke

* Parque Nacional Chapada dos Guimarães

* Reserva Florestal do Jarú

* Estação Ecológica do Jarí

* Floresta Estadual de Antimare

Parque Florestal de Macapá

Reserva Florestal de Curuá-Una

Reserva Biológica de Águas Emendadas

Reserva florestal ALBRÁS / ALUNORTE

Reserva Florestal da CVRD (Linhares - ES)

Parque Estadual de Mirador

Estação Experimental Lemos Maia (CEPLAC)

Reserva Biológica do Pau-Brasil

Locais sugeridos para conservação ex situ pela implantação de bancos de germoplasma (populações base), apenas na Amazônia:

ACRE, AMAPÁ, AMAZONAS, PARÁ, MATO GROSSO 


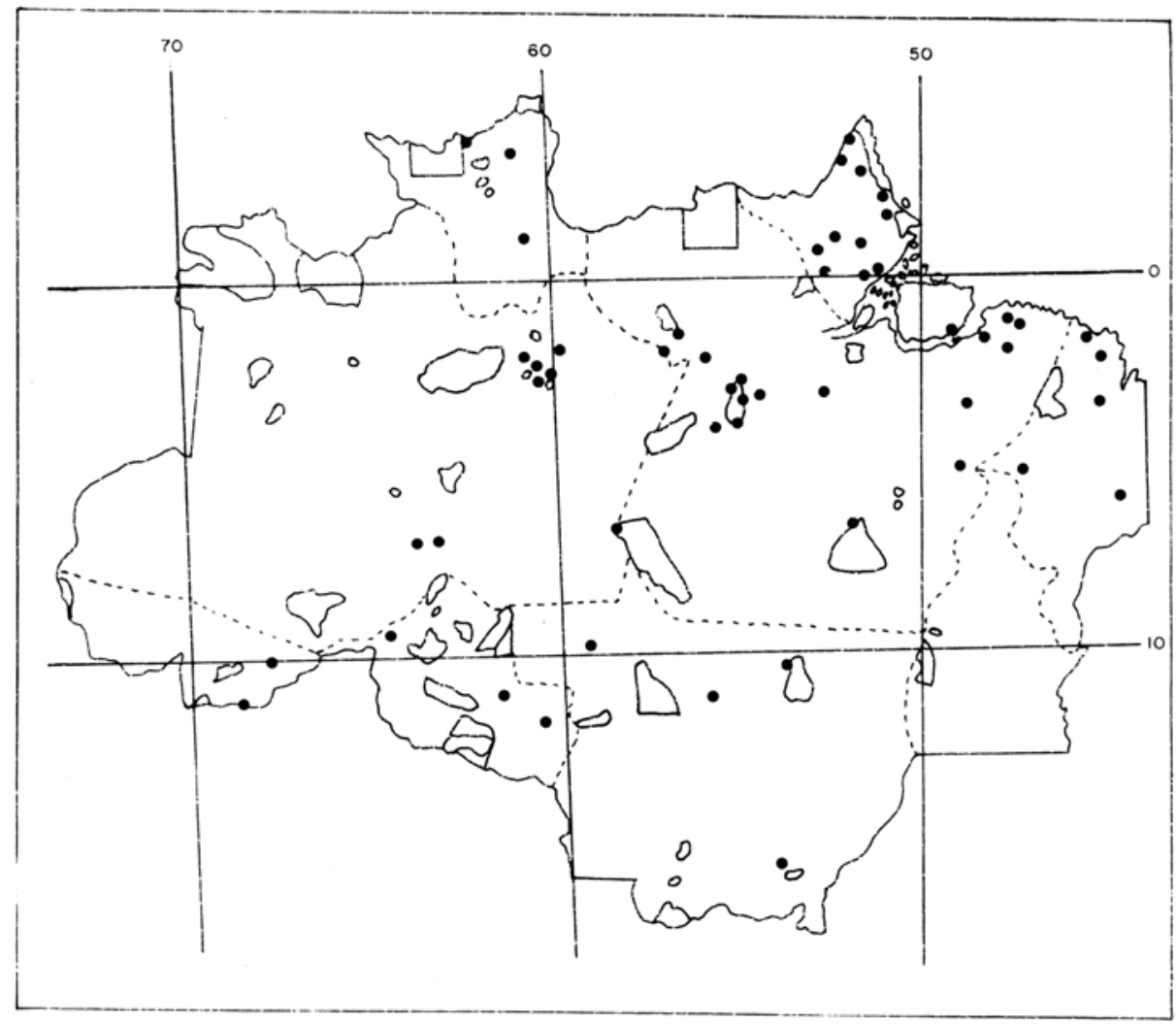

Figura 12 - Distribuição geográfica de Simaruba amara Aubl.. Marupá.

\section{Swietenia macrophylla King}

Família: Meliaceae

Nomes vulgares: Mogno, aguano (Mahogany, mundialmente).

Habitat: Habita áreas de mata de terra firme do Sul do Pará, Norte de Mato Grosso, Rondônia e Acre, em vegetação do tipo floresta ombrófila aberta, podendo ocorrer também em florestas de galeria. Ocorre em uma variedade de solos bem drenados ou periodicamente podendo estarem sujeitos a inundação.

Fenologia: varia em função da ocorrência.

JAN. FEV. MAR. ABR. MAI. JUN. JUL. AGO. SET. OUT. NOV. DEZ.

\begin{tabular}{|c|c|c|}
\hline & $\mathrm{XXXXXXXXXXXX}$ & Amér. Centr. e NE Amer. Sul \\
\hline SE da Amer. Sul & & XXXXXXXXXXXX \\
\hline
\end{tabular}

XXXXX Floração …. Frutificação 
a maturação dos frutos se dá após 10-12 meses da maturação.

Importância econômica:

É a mais valiosa entre as espécies madeireiras da América Latina tropical. Conhecida mundialmente, a madeira é utilizada no fabrico de móveis de luxo.

A espécie vem tornando-se escassa no seu habitat natural, visto a sua exploração intensa.

Locais onde supostamente está conservada (in situ) e propostas $\left(^{*}\right)$ para implantação de reservas genéticas:

* Reserva Florestal Juruena

* Reserva Biológica do Tapirapé

Reserva Florestal de Pedras Negras

* Reserva Biológica do Guaporé

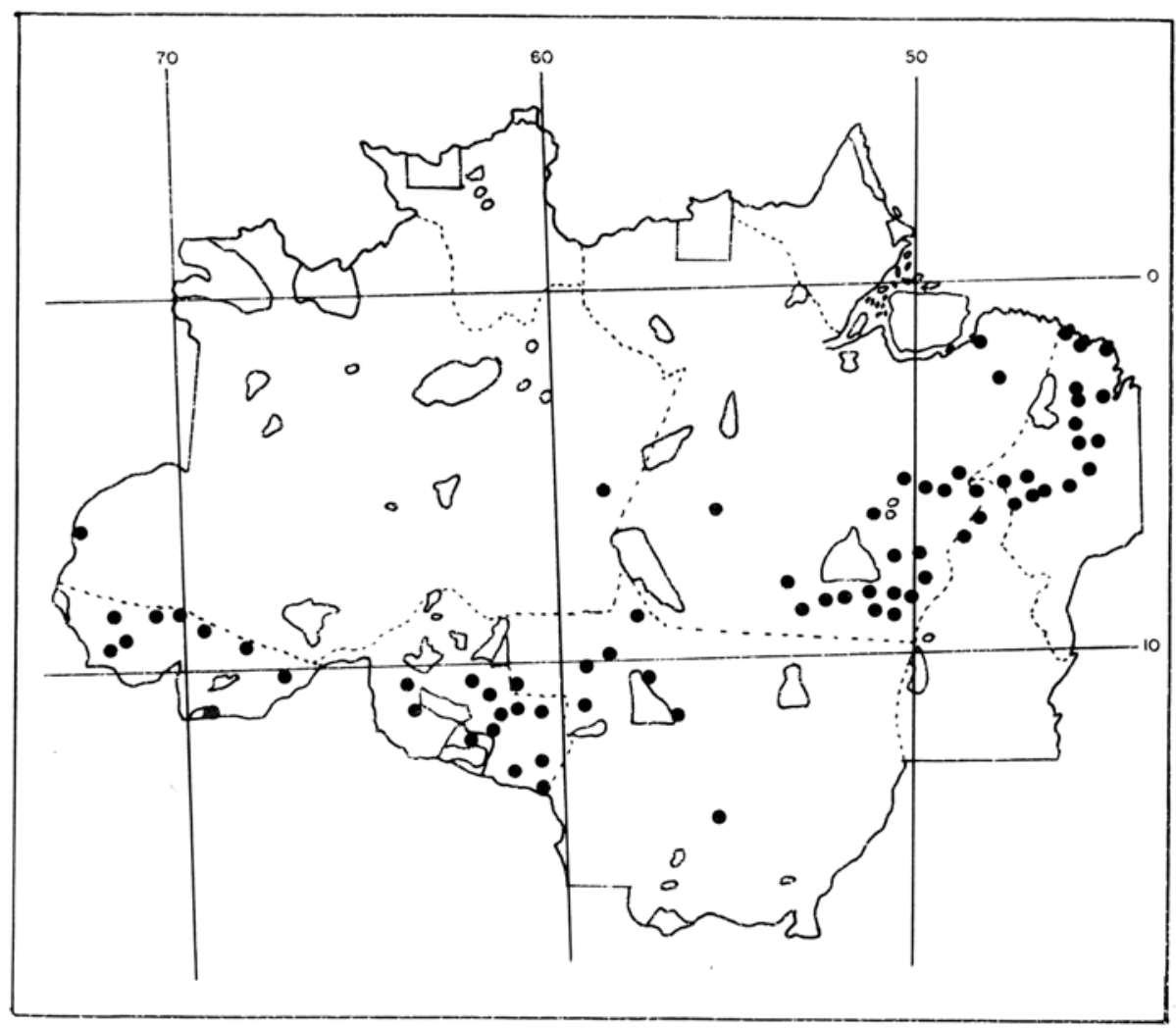

Figura 13 - Distribuição geográfica de Swietenia macrophylla King. Mogno. 
Parque Nacional dos Pacaás-Novos

* Estação Ecológica Rio Acre

Locais sugeridos para conservação ex situ pela implantação de bancos de germoplasma (populaçōes base):

Em áreas de baixa incidência da espécie, sob a forma de plantios consorciados de S. macrophylla com outras espécies, que não Meliaceae, preferencialmente nas regiöes de:

Manaus (existe plantio da espécie na área experimental do INPA, Reserva Ducke).

Imperatriz do Maranhão

Rondônia ou Acre

Virola sebifera Aubl.

Familia: Myristicaceae

Nomes vernaculares: ucuúba vermelha, árvore de sebo, bicuíba, árvore de cêra, ucuúba de folha larga.

Habitat: Espécie de ampla distribuição geográfica (principalmente na Amazônia e cerrado), ocorrendo em diferentes tipos de habitat, desde matas de terra firme (de baixas altitudes até no alto de serras - ca. $1.300 \mathrm{~m}$ altitude) até campos cerrados. Em função de sua distribuição ampla, a espécie apresenta formas muito variáveis de região para região, e em dependência do habitat de lugar para lugar, principalmente quanto à forma e consistência das folhas (c. f. Rodrigues, 1980).

Fenologia: Floração e frutificação têm sido observadas durante todo 0 ano em função da distribuição geográfica. 0 padrão mais comum está expresso abaixo (para Amazônia):

JAN. FEV. MAR. ABR. MAI. JUN. JUL. AGO. SET. OUT. NOV. DEZ.

$\begin{array}{lllll}\mathrm{xxx} & \mathrm{xXX} & \mathrm{xxx} & \mathrm{xxx}\end{array}$

$\begin{array}{llll}\mathrm{XXX} & \mathrm{XXX} & \mathrm{XXX}\end{array}$

XXXXX Floração …. Frutificação

Importância econômica:

Principalmente medicinal, a espécie é utilizada em todas suas partes. A casca (que é alucinogênica), a resina vermelha, o sebo e o óleo extraídos das amênbdoas dos frutos são utilizados para diversos problemas orgânicos.

Também é fornecedora de madeira empregada para embalagens e construção civil. 
Está sendo, cada vez mais, explorada como espécie madeireira para suprir a falta de outras madeiras consideradas de primeira qualidade que estão escasseando na região amazônica pelo extrativismo indiscriminado.

Locais onde supostamente está conservada (in situ) e propostas $\left(^{*}\right)$ para implantação de reservas genéticas (apenas para Amazônia):

Estação Estadual Jutaí-solimões

* Floresta Nacional do Tapajós

Reserva Florestal de Caxuanã

Parque Nacional da Amazônia

* Estação Ecológica do Jarí - Reserva Genética do Jarí

Estação Ecológica de Maracá

Estação Ecológica de Niquiá

Estação Ecológica de Caracaraí

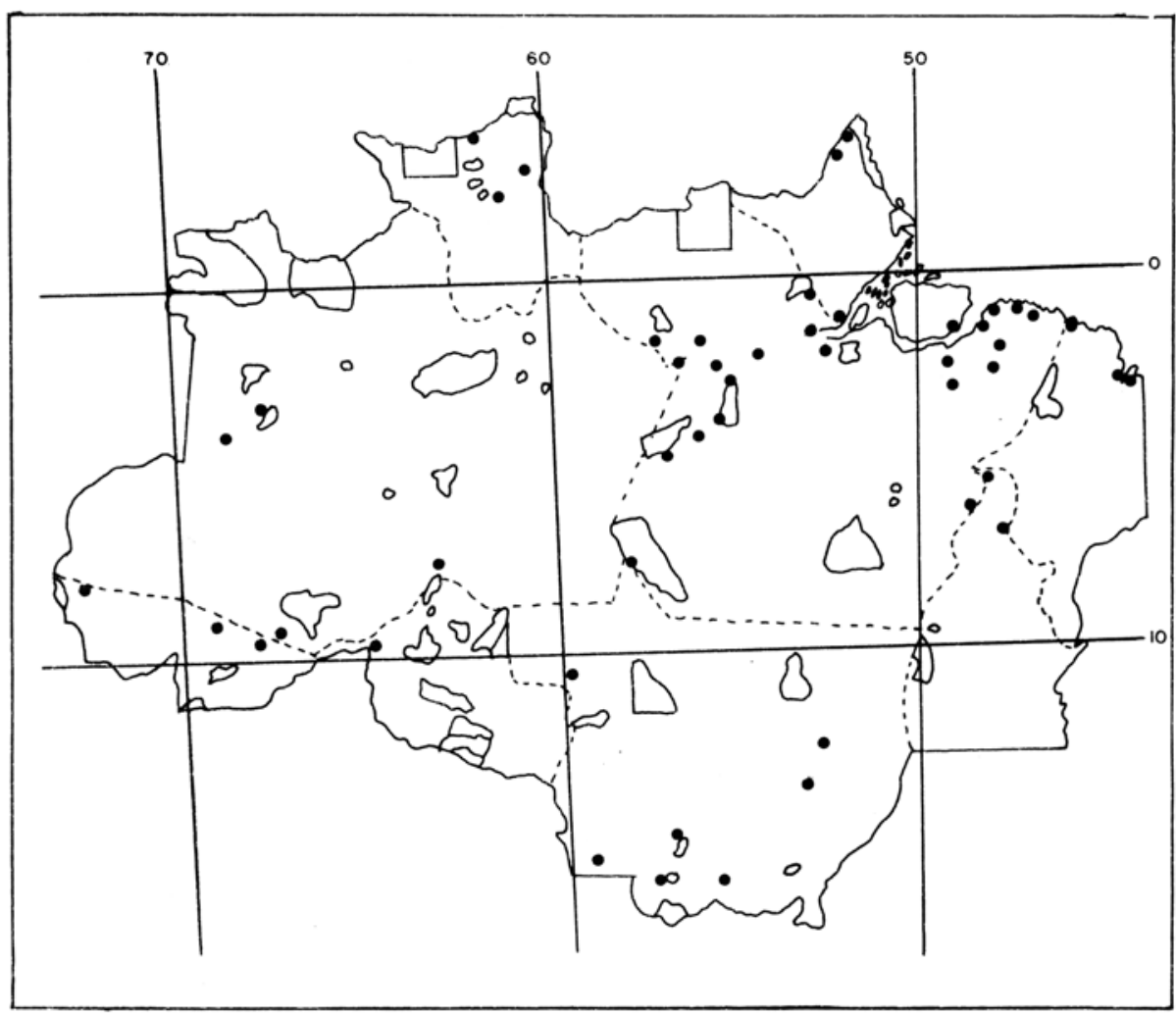

Figura 14 - Distribuição geográfica de Virola sebifera Aubl. Ucuúba 
Locais sugeridos para conservação ex situ pela implantação de bancos de germoplasma (populaçōes base):

Para a região amazônica, a proposta é de implantação de dois BAGs, um no Pará e um no Acre, considerando-se que a região Centro Oeste também deve ser contemplada com mais um BAG.

\section{Virola surinamensis Warb.}

Familia: Myristicaceae

Nomes vernaculares: ucuúba, ucuúba cheirosa, bicuíba, noz-moscada, árvore de sebo, andiroba.

Habitat: Tipicamente amazônica, a espécie habita área de várzeas e igapós (baixo Rio Negro), locais pantanosos e matas de terra firme. É diferenciada, pelos habitantes da Amazônia, em tipos segundo seu habitat:

Ucuúba verdadeira (terra firme)

Ucuúba de várzea (várzea)

Ucuúba de igapó (igapó), ou em dois (2) tipos segundo a coloração do lenho:

Ucuúba branca

Urucurana

Variações morfológicas em folhas, flores e frutos estão associados aos habitats e à ampla distribuição geográfica da espécie na região.

Fenologia: Varia principalmente em função da sua distribuição geográfica, podendo entretanto ser encontrada com flores e frutos durante todo o ano, nos diferentes locais de sua distribuição. Porém, floração e frutificação são mais freqüentes segundo o modelo abaixo:

JAN. FEV. MAR. ABR. MAI. JUN. JUL. AGO. SET. OUT. NOV. DEZ.

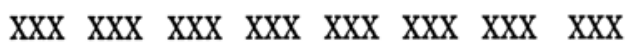

$\mathrm{xxx} \quad \mathrm{xxx} \quad \mathrm{xxx} \quad \mathrm{xxx} \quad \mathrm{xxx}$

XXXXX Floração

Frutificação

Importância econômica:

Potencialmente madeireira, a espécie é amplamente utilizada pelas indústrias de laminado e na produção de papéis kraft de boa qualidade (Rodrigues, 1980).

Constitui atualmente uma das plantas de maior valor econômico da Amazônia.

De suas sementes extrai-se o "sebo de ucuúba" de largo emprego em saboaria e fabricação de velas, além de uso medicinal regional. A casca também é utilizada na medicina popular. 
Locais onde supostamente está conservada (in situ) e propostas $\left(^{*}\right)$ para implantação de reservas genéticas:

* Reserva Florestal Ducke

* Reserva Biológica do INPA/SUFRAMA

* Estação Ecológica do Jarí

* Floresta Nacional do Tapajós

Floresta Nacional do Purús

Parque Nacional do Pico da Neblina

Locais sugeridos para conservação ex situ pela implantação de bancos de germoplasma (populações base):

Amazonas

Pará

Roraima

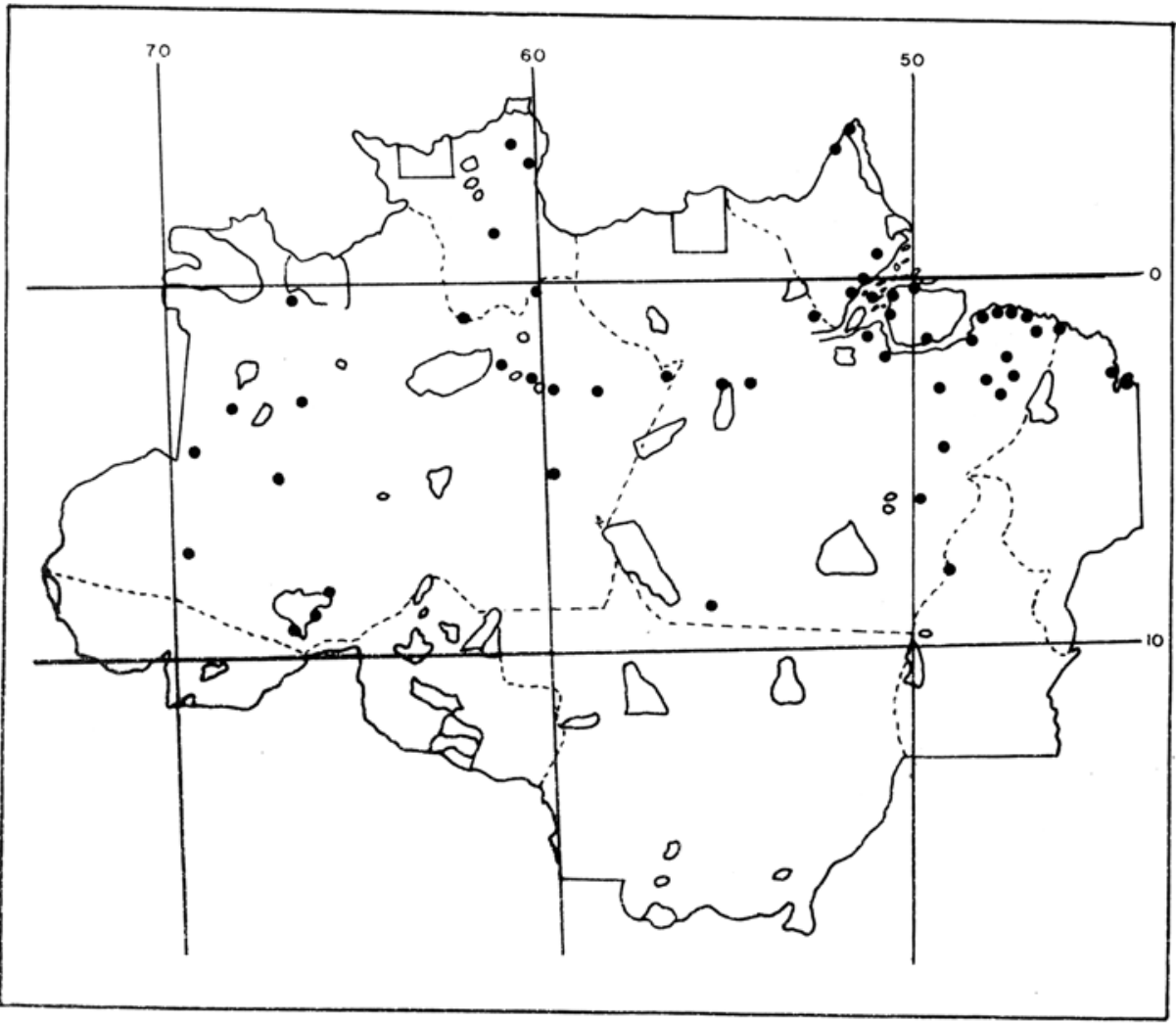

Figura 15 - Distribuição geográfica de Virola surinamensis Warb. Ucuúba 
Vouacapoua americana Aublet

Família: Caesalpiniaceae

Nome vulgar: Acapú (Bois d'épi de blé na França e Patridge Wood na Inglaterra). Habitat. Habita matas de terra firme (Amazônia Oriental) sobre solo argiloso ou sílico-argiloso.

Fenologia: Floração e frutificação sobrepostas e quase simultâneas.

JAN. FEV. MAR. ABR. MAI. JUN. JUL. AGO. SET. OUT. NOV. DEZ.

Floração e

início de frutificação

final de floração e

frutificação plena ano 1

ano 2

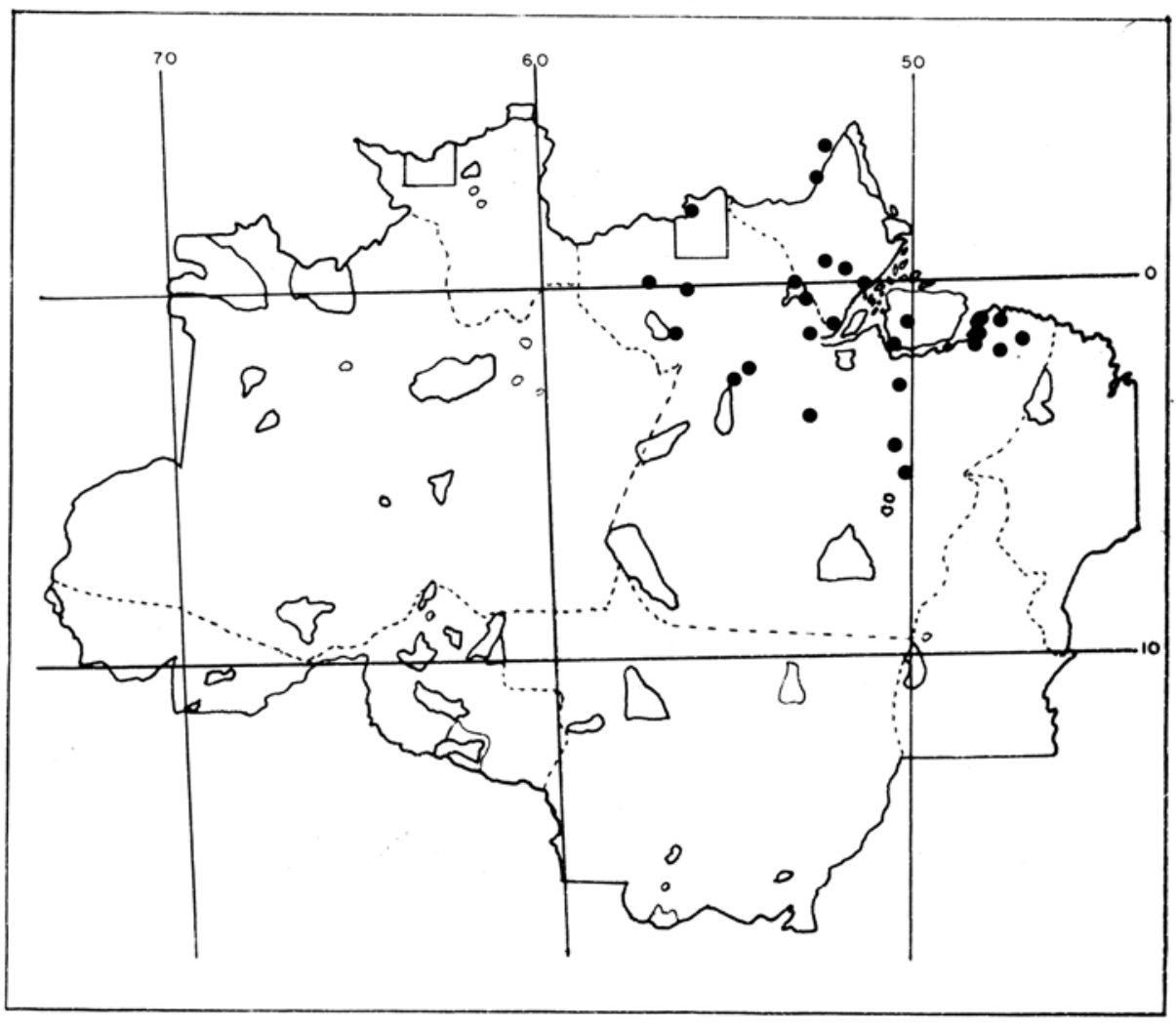

Figura 16 - Distribuição geográfica de Vouacapoua americana Aubl. Acapú. 
Importância econômica:

Desde o século passado a madeira era conhecida e exportada para a Europa, principalmente. Tanto a casaca quanto o lenho são adstringentes (medicinais). Os seringueiros utilizavam a fumaça da madeira queimada para defumar borracha.

Os caboclos da região chegam a distinguir 6 variedades pela madeira: amarela, branca, comum, pintada, preta ou pixua e rajada.

Locais onde supostamente está conservada (in situ) e propostas $\left(^{*}\right)$ para implantação de reservas genéticas:

Estação Ecológica do Jarí (R.G. do Jarî)

* Reserva Biológica do Rio Trombetas

Reserva Florestal de Tumucumaque

* Reserva Florestal de Caxiuanã

Reserva Florestal de Gorotiré

Locais sugeridos para conservação ex situ pela implantação de bancos de germoplasma (populaçōes base):

Estação Experimental de Curuá-Una.

Vouacapoua pallidior Ducke

Família: Caesalpiniaceae

Nome vulgar: Acapurana, acapú

Habitat: Matas de terra firme (AMAZÔNIA OCIDENTAL)

Fenologia:

JAN. FEV. MAR. ABR. MAI. JUN. JUL. AGO. SET. OUT. NOV. DEZ.

\begin{tabular}{|c|c|}
\hline & $\begin{array}{l}X X X X X X X X \\
X X X X X X X X\end{array}$ \\
\hline XXXXXXXX) & \\
\hline
\end{tabular}

XXXXX Floração …. Frutificação

Importância econômica

Sua maior utilização é como espécie madeireira, diferenciando-se de $V$. americana pela alopatria.

Locais onde supostamente está conservada (in situ) e propostas (*) para implantação de reservas genéticas:

* Reserva Florestal Ducke

* Reserva Florestal do Rio Negro

Parque Nacional do Pico da Neblina

Parque Nacional do Jaú

Estação Ecológica de Mamirauá 
Locais sugeridos para conservação ex situ pela implantação de bancos de germoplasma (populações base):

Estação Experimental de Silvicultura Tropical do INPA, Manaus-AM.

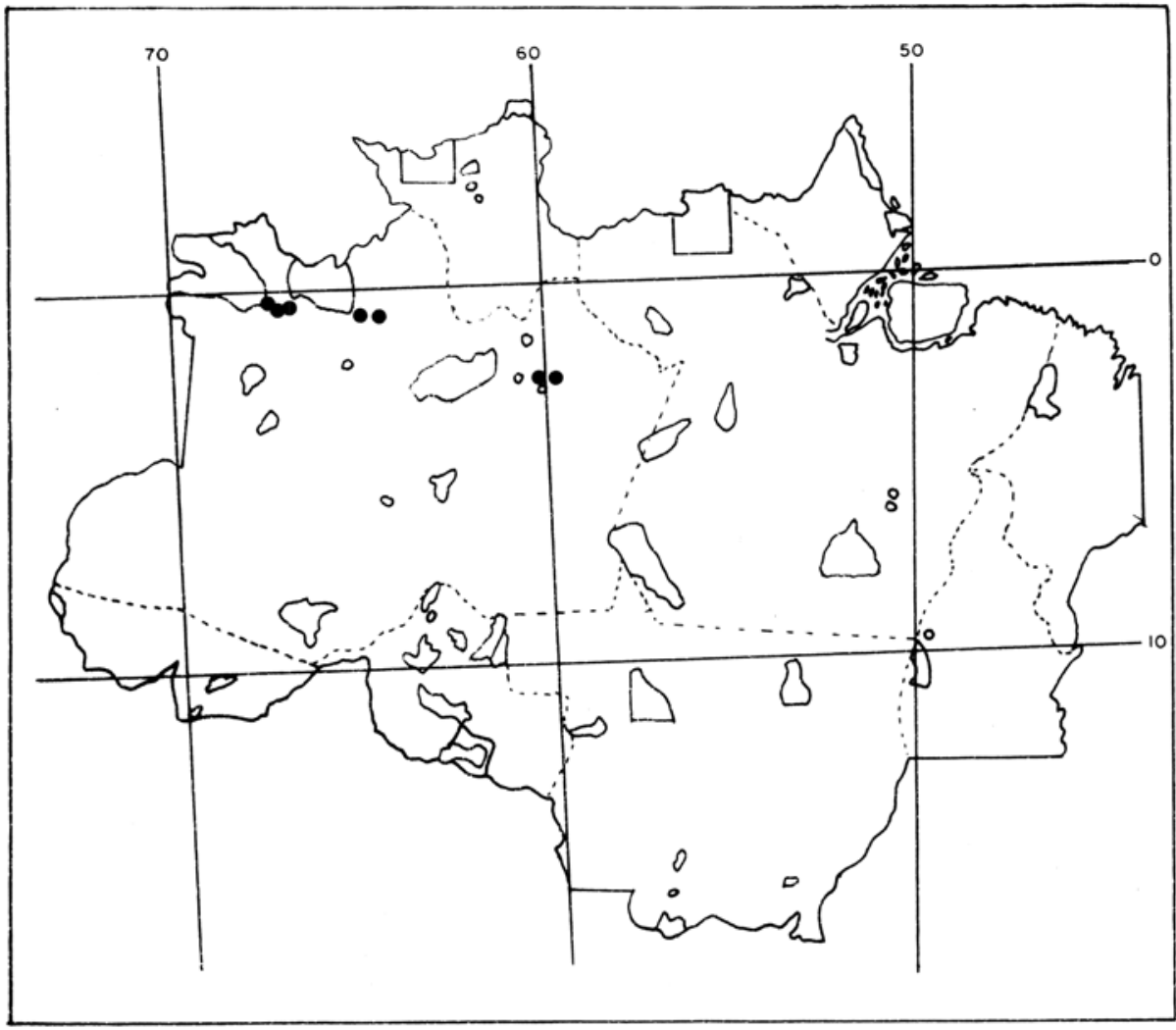

Figura 17 - Distribuição geográfica de Vouacapoua pallidior Ducke. Acapú.

A idéia de um programa de conservação in situ pela implantação de Reservas Genéticas em Unidades de Conservação, ou áreas contíguas a elas, pode ser o primeiro passo para a manutenção da variabilidade genética de espécies florestais nativas para utilização pelas gerações futuras (c.f. Roche, 1987).

A escolha das espécies prioritárias baseou-se não só no risco de extinção à qual estão predispostas, mas também ao uso atual ou potencial de uso pelas geraçōes futuras. Mesmo espécies não ameaçadas de extinção necessitam que sua variabilidade genética seja preservada e aquelas espécies que já estão sendo 
utilizadas pelo homem também estão predispostas à perda da variabilidade genética e portanto enquadradas como espécies prioritárias para conservação.

Como a conservação in situ permite uma "conservação evolutiva" (Roche \& Dourojeanni, 1984) e trata-se de um processo dinâmico, essa forma de manutenção da variabilidade genética é, portanto, a mais adequada para as espécies florestais nativas.

Entretanto, para muitas dessas espécies, somente a conservação in situ pode não garantir a salvaguarda do seu pool gênico e assim, a conservação $e x$ situ, deve ser também considerada.

Ex situ a espécie pode estar preservada na forma de plantios à campo, pode ser mantida através de suas sementes acondicionadas em câmaras de armazenamento e ainda ser conservada in vitro. Como ainda é pouca a quantidade de informaçōes que se tem a respeito da recalcitrância ou ortodoxia das sementes de florestais nativas, o que restringe as tentativas de armazenamento de sementes, escolheu-se o método complementar de conservação ex situ a campo (Bancos de Germoplasma) onde a variabilidade genética possível de existir em outras áreas, que não as contempladas pela implantação de Reservas genéticas, seria coletada e preservada nas área de plantios, em locais adequados a cada espécie.

O primeiro passo para o estudo dos locais adequados para conservação de determinada espécie é saber a sua ocorrência (distribuição geográfica e habitats) para que os estudos subseqüentes possam ser executados (Roche, 1987). Outro fator importante que influi tanto para coleta quanto conservação é a fenologia da espécie e suas variações de região para região ou de habitat para habitat, o que pode significar estratégias diferentes para as espécies.

A partir da ocorrência e da fenofase das espécies é possível planejar viagens de coleta e propôr locais prioritários para os estudos de ecologia de populações. Assim, as áreas propostas neste trabalho foram baseadas principalmente na distribuição geográfica, nos habitats e nas variações morfológicas apresentadas pelas espécies estudadas, considerando-se apenas a região amazônica.

Muitas das áreas aquí propostas para implantação de Reservas Genéticas piloto, beneficiarão não apenas uma, mas várias espécies de importância sócioeconômica para a região e para o país, bem como espécies que até o momento não se tem informaçōes sobre seu potencial de utilização pelo homem.

Além de conservar a variabilidade genética das espécies vegetais em foco, as Reservas Genéticas estarão preservando os demais seres vivos contidos em suas áreas, incluindo polinizadores, dispersores e predadores que participam do processo evolutivo.

As principais Unidades de Conservação recomendadas como prioritárias para implantação de Reservas Genéticas são: Floresta Nacional do Tapajós, Reserva Florestal do Rio Negro, Reserva Florestal Ducke, Estação Ecológica do Jarí (já possui uma área destinada à Reserva Genética), Parque Nacional da Amazônia, Estação Ecológica Rio Acre, Reserva Florestal do jaru, Reserva Biológica 
INPA/SUFRAMA, Reserva Florestal Juruena, Reserva Biológica do Rio Trombetas.

Os locais para implantação de Bancos de Germoplasma (populações base), está correlacionada com as regiōes de ocorrência natural das espécies, ou propostos de serem implantados em regiões onde não há grandes aglomerados de determinada espécie que apresente problemas com pragas e doenças que interfiram na sua sobrevivência; como no caso específico das espécies da família Meliaceae, as quais apresentam o ataque do broto terminal por Hypsypylla grandela e por isso não resistem a plantios homogêneos.

A idéia de se propôr o resgate de germplasma de cada espécie por região, ou habitat, de ocorrência natural, permite que o material não necessite aclimatação devido ao deslocamento para locais onde a espécie possa sofrer interferências ambientais que atentem contra a sua sobrevivência.

Assim, locais escolhidos para conservação ex situ a campo basearam-se em Unidades de Conservação que já possuem áreas específicas para plantios ou possibilidades para implantação. A sugestão de mais de um local para instalação de Bancos de Germoplasma baseou-se na distribuição ecológica das espécies e no problemas específicos relevantes, anteriormente mencionados para as Meliaceae.

\section{Referências Bibliográficas}

ALENCAR, J. da C. 1982. Estudos silviculturais de uma população natural de Copaifera multijuga Hayne - Leguminosae, na Amazônia Central. 2 - Produção de óleo resina. Acta Amazonica, 12(1):75-89.

ARAÚJO, V.C. 1970. Fenologia de Essências Florestais Amazônicas. I. Boletim do Instituto Nacional de Pesquisas da Amazônia (INPA). Manaus, Pesquisas Florestais, 4:1-25.

CARVALHO, J.O.P. 1983. Abundância, freqüência e grau de agregação do Paurosa (Aniba duckei Kostermans) na Floresta Nacional do Tapajós. EMBRAPA. Boletim de Pesquisa, 53:1-18.

CORREA, M. PIO \& L. de A. PENNA. 1984. Dicionário das Plantas úteis do Brasil e das exóticas cultivadas. Brasília, IBDF. 6v.

FAO. 1986. Data book on endangered forest tree and shrub species and provenances. FO: MISC/81/11. FAO, ROMA.

KERR, W.E. 1978. Pontos importantes na colonização da Amazônia. III Simpósio anual sobre "Brasil em explosão demográfica". São Paulo, Secretaria de Ciência e Cultura, Academia de Ciências do Estado de São Paulo.

KUBITZKI, K. \& S. RENNER. 1982. Aniba. LAURACEAE I. Flora Neotropica: 31. New York Botanical Garden. New York. 84p.

LEITE, A.M.C., A.N. SALOMÃO \& E. LLERAS. 1991.Áreas prioritárias para 
conservação de cinco espécies florestais na Floresta Tropical Úmida. Trabalho apresentado no Simpósio Internacional "O Desafio das Florestas Neotropicais". Curitiba-PR, 7 a 11/04/1991. (Entregue para publicação pela EMBRAPA/CENARGEN em março de 1991).

LOUREIRO, A.A. \& M. F. da. Silva. 1968. Catálogo das Madeiras da Amazônia. Ministério do Interior. SUDAM. Belém. Volumes I e II.

ROCHE, L. \& M.J. DOUROJEANNI. 1984. Manual sobre la conservación in situ de los recursos genéticos de especies leñosas tropicales. FAO, Roma. 161p.

ROCHE, L. 1987. Forest Genetic Resources Conservation, Brazil. Consultant Final Report IICA/EMBRAPA - PROCENSUL II. 36p.

RODRIGUES, W.A. 1980. Revisão taxonômica das espécies de Virola Aublet (Myristicaceae) do Brasil. Acta Amazonica, 10(1): suplemento. 127p. 